\title{
Disaggregation of SMOS soil moisture over West Africa using the Temperature and Vegetation Dryness Index based on SEVIRI land surface parameters
}

Article

Accepted Version

Creative Commons: Attribution-Noncommercial-No Derivative Works 4.0

Tagesson, T., Horion, S., Zaldo Fornies, V., Mendiguren Gonzalez, G., Bulgin, C. E., Ghent, D. and Fensholt, R. (2018) Disaggregation of SMOS soil moisture over West Africa using the Temperature and Vegetation Dryness Index based on SEVIRI land surface parameters. Remote Sensing of Environment, 206. pp. 424-441. ISSN 0034-4257 doi: https://doi.org/10.1016/j.rse.2017.12.036 Available at https://centaur.reading.ac.uk/74711/

It is advisable to refer to the publisher's version if you intend to cite from the work. See Guidance on citing.

To link to this article DOI: http://dx.doi.org/10.1016/j.rse.2017.12.036

Publisher: Elsevier

All outputs in CentAUR are protected by Intellectual Property Rights law, including copyright law. Copyright and IPR is retained by the creators or other copyright holders. Terms and conditions for use of this material are defined in the End User Agreement. 


\section{www.reading.ac.uk/centaur}

\section{CentAUR}

Central Archive at the University of Reading

Reading's research outputs online 


\title{
Disaggregation of SMOS soil moisture over West
} Africa using the Temperature and Vegetation Dryness Index based on SEVIRI land surface parameters

\author{
T. Tagesson ${ }^{1,2, *,+}$, S. Horion ${ }^{1, *}$, H. Nieto ${ }^{3}$, V. Zaldo Fornies ${ }^{1}$, G. Mendiguren González ${ }^{4,5}$, C. E. \\ Bulgin $^{6}$, D. Ghent ${ }^{7}$, R. Fensholt ${ }^{1}$ \\ ${ }^{1}$ Department of Geosciences and Natural Resource Management (IGN), University of Copenhagen, Øster Voldgade 10, \\ DK-1350 Copenhagen, Denmark \\ ${ }^{2}$ Department of Physical Geography and Eosystem Analysis, Lund University, Sölvegatan 12, SE- 22362 Lund, \\ ${ }^{3}$ Efficient Use of Water in Agriculture Program, Institut de Recerca i Tecnologia Agroalimentàries (IRTA), Fruitcentre, \\ Parc Cientific i Tecnològic Agroalimentari, Lleida 25003, Spain \\ ${ }^{4}$ Department of hydrology, Geological Survey of Denmark and Greenland (GEUS), Øster Voldgade 10, DK-1350 \\ Copenhagen, Denmark \\ ${ }^{5}$ Department of Environmental Engineering, Technical University of Denmark, 2800 Kgs. Lyngby, Denmark \\ ${ }^{6}$ Department of Meteorology, University of Reading, 3 Earley Gate, PO Box 238, Reading, United Kingdom \\ ${ }^{7}$ Space Research Centre, University of Leicester, University Road Leicester, LE1 7RH, United Kingdom \\ *These two authors contributed equally to this research. \\ ${ }^{+}$Corresponding author: e-mail: torbern.tagesson@ign.ku.dk; Tel. +46 704993936
}

\section{Abstract}

The overarching objective of this study was to produce a disaggregated SMOS Soil Moisture (SM) product using land surface parameters from a geostationary satellite in a region covering a diverse range of ecosystem types. SEVIRI data at 15 minute temporal resolution were used to derive the Temperature and Vegetation Dryness Index (TVDI) that served as SM proxy within the disaggregation process. West Africa $\left(3^{\circ} \mathrm{N} 26^{\circ} \mathrm{W} ; 28^{\circ} \mathrm{N} 26^{\circ} \mathrm{E}\right)$ was selected as a case study as it presents both an important North-South climate gradient and a diverse range of ecosystem types. The main challenge was to set up a methodology applicable over a large area that overcomes the constraints of SMOS (low spatial resolution) and TVDI (requires similar atmospheric forcing and triangular shape formed when plotting morning rise temperature versus fraction of vegetation cover) in order to produce a $0.05^{\circ}$ resolution disaggregated SMOS SM product at the sub-continental scale. 
Consistent cloud cover appeared as one of the main constraints for deriving TVDI, especially during the rainy season and in the southern parts of the region and a large adjustment window $(105 \times 105$ SEVIRI pixels) was therefore deemed necessary. Both the original and the disaggregated SMOS SM products described well the seasonal dynamics observed at six locations of in situ observations. However, there was an overestimation in both products for sites in the humid southern regions; most likely caused by the presence of forest. Both TVDI and the associated disaggregated SM product was found to be highly sensitive to algorithm input parameters; especially for conditions of high fraction of vegetation cover. Additionally, seasonal dynamics in TVDI did not follow the seasonal patterns of SM. Still, its spatial heterogeneity was found to be a good proxy for disaggregating SMOS SM data; main river networks and spatial patterns of SM extremes (i.e. droughts and floods) not seen in the original SMOS SM product were revealed in the disaggregated SM product for a test case of JulySeptember 2012. The disaggregation methodology thereby successfully increased the spatial resolution of SMOS SM, with potential application for local drought/flood monitoring of importance for the livelihood of the population of West Africa.

Keywords: TVDI; SMOS; disaggregation; downscaling; soil moisture; SEVIRI; sensitivity analysis

\section{Introduction}

Complex interactions of energy exchange are taking place between different components of the Earth system, notably between the atmosphere, hydrosphere and biosphere (Bonan 2008). A better understanding of such interactions is of high societal relevance for improving assessment of carbon and water fluxes as well as for preventing, monitoring and forecasting extreme events. However, it implies the accurate assessment of essential climate variables, such as soil moisture (SM) that is key to determining the water fluxes between the land surface and the atmosphere (Vinukollu et al. 2011). 
Since the 1970s, data from Earth Observation (EO) satellite platforms have been used to overcome the limitations of ground sensors thereby providing timely information on the spatial distribution of SM. Soil moisture affects the emission and absorption of electromagnetic radiation in different regions of the spectrum: 1) MicroWave (MW) backscattered or emitted energy from the ground surface, particularly in the low-frequency microwave range, from 1 to $10 \mathrm{GHz}$, allows the dielectric constant to be related to SM (Schmugge 1978; Stisen et al. 2008); 2) When the soil is wet the energy balance of the surface is controlled by evaporation from the soil surface and vegetation transpiration and lower surface temperatures are expected in wet soils than in drier soils during daytime (Schmugge 1978). This effect can be captured in the Thermal InfraRed (TIR) region of the electromagnetic spectrum. Additionally, if multiple observations of the land surface are acquired at different times throughout the day, diurnal variability in emitted radiation can be related to the soil thermal inertia (a property that describes the resistance of a material to temperature change) (Wang et al. 2006) and consequently serves as a good indicator of evapotranspiration and SM (Minacapilli et al. 2009; Stisen et al. 2008); and 3) in the optical domain (350-2500 nm), an increase of SM produces an overall decrease in albedo (Bach and Mauser 1994) and specific absorption features in the Short-Wave Infrared Region (SWIR) (Sadeghi et al. 2015).

Each of these spectral regions have advantages and disadvantages for mapping SM (Kerr 2007; Moran et al. 2004). Microwave sensors are insensitive to atmospheric disturbances, but they usually require larger pixel sizes than sensors in the optical or thermal infrared domain, due to the lower emitted energy in this region. This is the case for the Soil Moisture and Ocean Salinity (SMOS) (average pixel size $43 \mathrm{~km}$ ) (Kerr et al. 2012) and the Soil Moisture Active Passive (SMAP) (30km) (Panciera et al. 2014) missions dedicated to monitor SM, rendering such products less suited for spatially explicit studies of the hydrological cycle at the local scale. Unlike MW sensors, optical and TIR sensors are greatly affected by the atmosphere, and allows a higher spatial resolution of 
$98 \quad \mathrm{TVDI}=\frac{\mathrm{LST}-\mathrm{LST}_{\min }}{\mathrm{LST}_{\max }-\mathrm{LST}_{\min }}$ cover.

measurements. The Spinning Enhanced Visible and InfraRed Imager (SEVIRI) instrument aboard the geostationary satellite Meteosat Second Generation (MSG) is an optical and TIR sensor centred over Africa that scans the full Earth disk every $15 \mathrm{~min}$. This high temporal resolution is a major advantage since it allows estimates of soil thermal inertia (morning rise temperature; dTS) (Stisen et al. 2008) and it increases the probability of obtaining cloud free observations for areas with frequent cloud

Given the advantages/disadvantages of different EO retrievals, combining high and low spatial resolution data for improving the SM spatial variability has received considerable scientific attention recently (Malbéteau et al. 2016; Merlin et al. 2012; Peng et al. 2017; Wang et al. 2016). Methods for disaggregation of SM products can be classified into three major groups: (1) satellite based methods; (2) methods using an array of geoinformation data and (3) model based methods (Peng et al. 2017). Among satellite based methods, an integration of coarse spatial resolution microwave observations with optical/thermal EO retrievals using a downscaling factor is most commonly used (Peng et al. 2017; Wang et al. 2016). One example of an optical/thermal remote sensing metric closely related to SM variability is the Temperature-Vegetation Dryness Index (TVDI) (Sandholt et al. 2002) based on the triangle/trapezoid (hereinafter called triangle) method, since it empirically delimits the triangle formed when plotting the Land Surface Temperature (LST) or dTS versus a Vegetation Index (VI) (Figure 1) (Carlson et al. 1995; Carlson et al. 1990; Moran et al. 1994; Sandholt et al. 2002; Stisen et al. 2008; Sun et al. 2012; Tang and Li 2017). TVDI is most commonly calculated as:

where LST is the LST for a given pixel; $\mathrm{LST}_{\min }$ is minimum LST extracted empirically from the

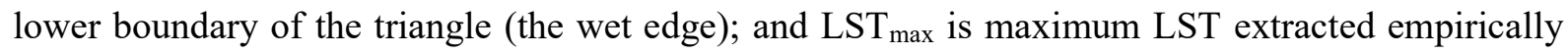


from the upper boundary of the triangle (the dry edge) for the vegetation index value of the specific pixel (Figure 1) (Sandholt et al. 2002). The dry edge represents dry soils with low evaporation rates causing LST to be at its maximum as a function of the vegetation fraction whereas the wet edge represents wet soils where the evaporation rate occurs near its potential and thus LST is at its minimum and close to the air temperature. Between these two edges, all intermediate conditions can occur, and all SM conditions can consequently be represented within the LST-VI triangle space (Figure 1) (Sandholt et al. 2002).

The triangle approach has been used in several attempts to disaggregate low spatial resolution microwave SM retrievals. At a field site in the north eastern Tibetan plateau, Wang et al. (2016) investigated the applicability of the TVDI for determining a downscaling factor for multiple source microwave based SM data from the European Space Agency (ESA) Climate Change Initiative (CCI) (Dorigo et al. 2012). At the Iberian peninsula, SMOS SM have been disaggregated using the triangle technique with MODerate resolution Imaging Spectroradiometer (MODIS) LST as input data (Piles et al. 2011; Piles et al. 2014), and in an attempt to overcome the issue of frequent cloud cover MSG SEVIRI LST at 15-min temporal resolution was also used (Piles et al. 2016). Another common approach for disaggregation of SMOS SM is to use the DisPATCH (Disaggregation based on Physical And Theoretical scale CHange) model, which combines thermal and optical imagery in a contextual algorithm to derive Soil Evaporative Efficiency (SEE), and then relate SEE to SM through a physically based model (Djamai et al. 2015; Malbéteau et al. 2016; Merlin et al. 2010; Merlin et al. 2012).

Several assumptions and prerequisites need to be taken into account when applying the triangle method: 1) the presence of all SM and vegetation cover conditions are needed within the spatial domain applied (Sandholt et al. 2002; Stisen et al. 2008); 2) the dimensions of the spatial domain have to be large enough to collect a sufficient amount of LST-VI cases to adequately define the 
triangle shape (de Tomás et al. 2014); 3) factors like land cover type and topography should be taken into account to ensure the applicability of the method (Hassan et al. 2007); 4) variations in LST must simply reflect variability in SM, which requires other surface properties and atmospheric forcing to be homogeneous; e.g. available energy (net radiation minus ground heat flux), meteorological conditions over the studied area (solar radiation, total column water vapour, air temperature, and wind speed) as well as homogeneous surface roughness to ensure similar conditions affecting the turbulent heat transport (Gillies and Carlson 1995; Moran et al. 1994); and 5) the strong dependence on the endmembers forming the triangular shape implies that a specific TVDI is only comparable with TVDI estimates derived with the same endmember values. As taken together, these preconditions are difficult to fulfil over the entire triangle space (from bare soil to full vegetation cover; from humid to dry conditions), which limit the applicability of the TVDI approach to localized (spatially and temporally) scales (de Tomás et al. 2014; Garcia et al. 2014; Stisen et al. 2008; Tang and Li 2015) as when attempting to cover larger regions there is a high risk of violating these stated preconditions.

Previous studies have used LST directly in the disaggregation process; however combining soil thermal inertia (dTS) based on MSG SEVIRI LST at 15-min temporal resolution with the TVDI approach allows for a more direct estimate of evaporative fraction (Stisen et al. 2008), which can be implemented in the physically based disaggregation methodology behind DisPATCH (Merlin et al. 2012). The overarching objective of this study was to produce a high-resolution disaggregated SMOS SM product for a region covering a diverse range of ecosystem types. We aimed at doing so by disaggregation of low spatial resolution MW data (SMOS) using dTS based on higher spatial and temporal resolution optical data (SEVIRI). We applied the physically based disaggregation methodology behind DisPATCH (Merlin et al. 2012), thereby taking advantage of both types of EO retrievals for SM assessment and accounting for their respective inherent limitations. The main research questions addressed were: 
149 How can TVDI derived from SEVIRI based dTS be implemented to resolve the SM spatial 150 heterogeneity within a SMOS pixel when produced at sub-continental scale over West Africa? What 151 are the methodological constraints to overcome in order to produce time series of high-resolution 152 disaggregated SMOS SM product over regions covering a wide spectrum of ecosystem types ranging 153 from desert to tropical forests?

154 To address these research questions, time series of SMOS SM and time series of LST and Fractional 155 Vegetation Cover (FVC) from the MSG SEVIRI instrument were acquired for the period 2010-2015. 156 TVDI was estimated for tile-based adjustment windows on SEVIRI dTS and FVC. The TVDI 157 estimates were incorporated into a disaggregation methodology to produce high resolution 158 disaggregated SMOS SM product for West Africa. The sensitivity of TVDI and disaggregated SMOS 159 SM to the input parameters were quantified. The original and the disaggregated SMOS SM products 160 were evaluated against in situ SM from sites within the International Soil Moisture Network (ISMN). 161 Finally, the spatial patterns of disaggregated SM products were evaluated for a specific case of 162 extreme SM conditions (droughts and floods) in the Sahel 2012. 


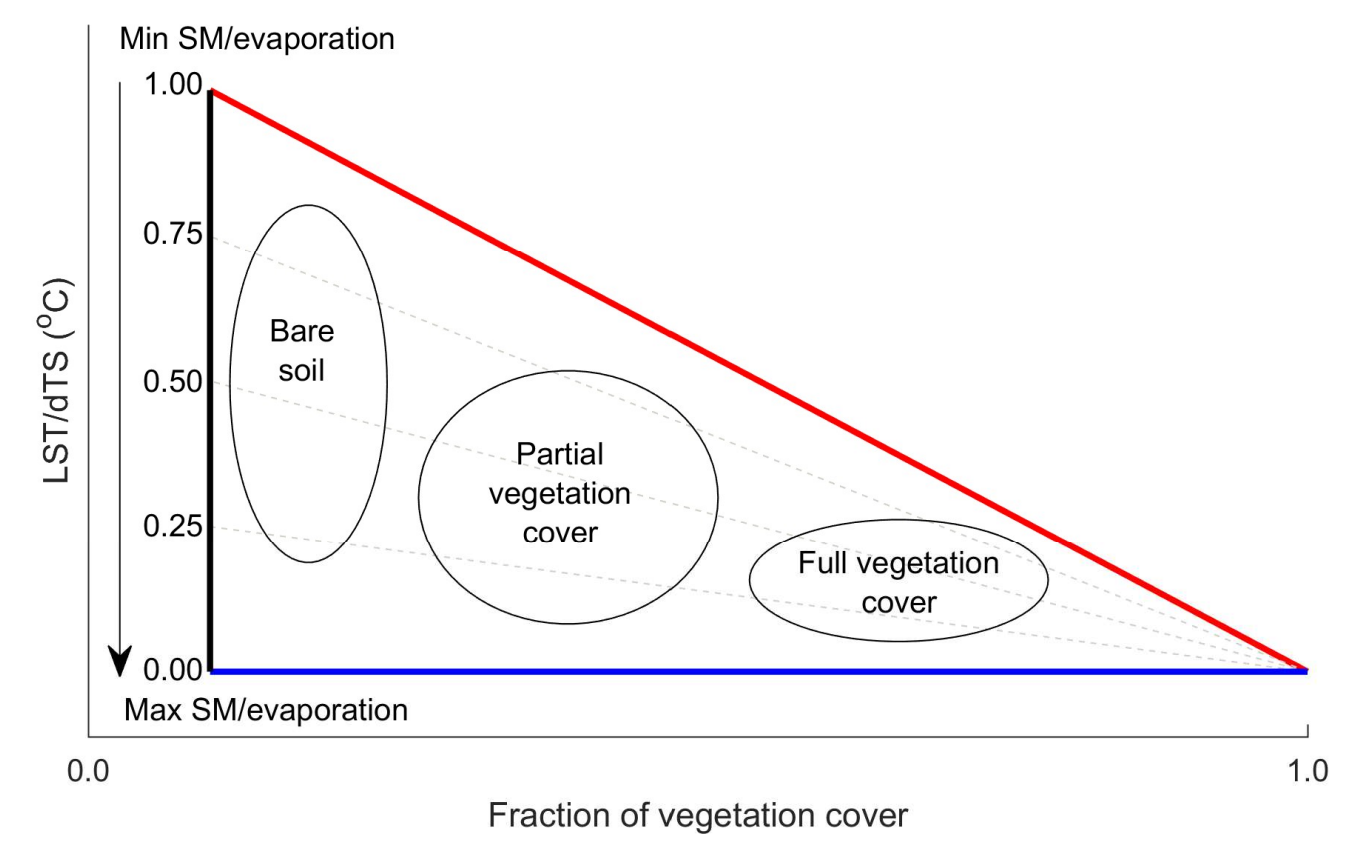

Figure 1. Conceptual triangle space with the land surface temperature (LST) or morning rise temperature (dTS) on the y-axis and Fraction of Vegetation Cover (FVC) on the x-axis. The blue line is the wet edge (TVDI=0.00) and the red line is the dry edge (TVDI=1.00). The grey dotted lines are TVDI examples of 0.25, 0.50, and 0.75. The figure is adapted from Peng et al. (2017).

\section{Materials and Methods}

\subsection{Study area}

West Africa was selected as research area for this study (Figure 2) as the climate varies from hot desert in the north to tropical forest climate in the south. The area $\left(3^{\circ} \mathrm{N} 26^{\circ} \mathrm{W} ; 28^{\circ} \mathrm{N} 26^{\circ} \mathrm{E}\right)$ stretches from Senegal in the west to Chad in the east. The climate is controlled by the West African Monsoon and is characterized by a north-south gradient of increasing annual precipitation. The large gradient in precipitation totals is reflected by increasing biomass from north to south as reflected in the fractional vegetation cover (Figure 2). The study area constitutes of $1.06 \times 10^{4}$ SMOS pixels and $5.20 \times 10^{5}$ SEVIRI pixels. 


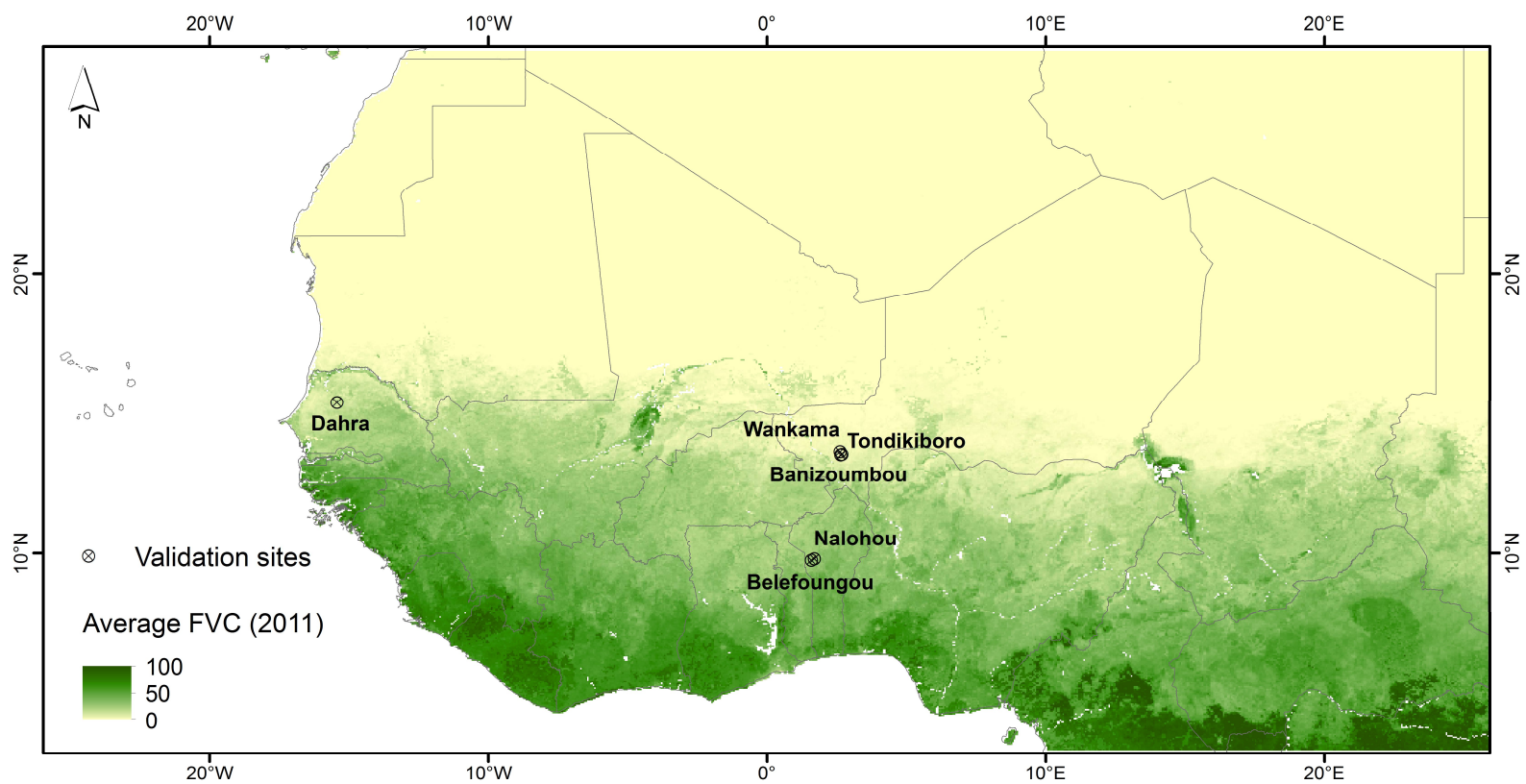

Figure 2. Study area with the location of the in situ validation sites. The averaged fraction of vegetation cover (FVC) for year 2011 is used as background to illustrate the important north-south gradient in vegetation cover.

\subsection{Data collection and pre-processing}

\subsubsection{SMOS soil moisture}

The SMOS mission includes a passive interferometric radiometer and is the first satellite mission operating at L-band $(1.4 \mathrm{GHz})$. The L-band is less sensitive to green vegetation components and the SMOS multi-angular acquisition capability is additionally used to separate the soil and vegetation signal (Kerr 2007; Wigneron et al. 2007). The SMOS level 2 version-62x SM product was used in this study. We downloaded the SMOS data from 1 June 2010 until 31 December 2015 for the study area. SMOS SM is an average of SM at $0-5 \mathrm{~cm}$ depth. The revisiting time at the equator is every 3 days for both ascending and descending passes, which are sun synchronous at 6 am ascending and 6 pm descending. The geolocation accuracy of SMOS is $500 \mathrm{~m}$. The sampling grid of the SMOS data is the Discrete Global Grid (DGG), and it has a node separation of $14.99 \mathrm{~km}$. This is higher than the natural footprint size of SMOS, ranging from 30 to $90 \mathrm{~km}$ (average $43 \mathrm{~km}$ ) depending on viewing 
angle. Data were reprojected to WGS-84 geographic coordinates using a bilinear resampling method. We used a $0.35^{\circ}$ grid $(\sim 40 \mathrm{~km}$; which is close to the average natural footprint size of SMOS and is easily dividable with the chosen SEVIRI pixel size) and averaged the SMOS SM estimates of the DGG nodes falling within a $\pm 0.1^{\circ}$ area in the centre of each pixel. We only used these central nodes as these are assumably least influenced by neighbouring pixels.

\subsubsection{Land surface temperature}

Land surface temperatures from SEVIRI from 1 January 2010 to 31 December 2015 were acquired following the procedure described in (Nieto et al. 2011; Rasmussen et al. 2011; Stisen et al. 2007). SEVIRI LST fields are available every 15 minutes for the entire MSG disk centred at $0^{\circ}$ longitude and with a native pixel sampling size of $3 \mathrm{~km}$. For consistency with the retrieved FVC data (see below), it was resampled using nearest neighbour to a spatial resolution of $0.05^{\circ}$.

LST was calculated based on SEVIRI channels centered at 10.8 and $12 \mu \mathrm{m}$. The EUropean organisation for the exploitation of METeorological SATellites (EUMETSAT) NoWCasting \& very short range forecasting Satellite Application Facility (NWC SAF) software (version 2013) was used for converting data to top-of-atmosphere (TOA) brightness temperatures. TOA brightness temperatures were atmospherically corrected for surface emissivity, atmospheric attenuation along the path and emissivity of downward radiation. Spectral emissivity was estimated based on soil and vegetation emissivity endmember values, scaled by the Normalised Difference Vegetation Index (NDVI) and a look-up table (Trigo et al. 2008). SEVIRI NDVI was calculated from daily nadir Bidirectional Reflectance Distribution Function (BRDF)-adjusted reflectance corrected using the Simplified Method for Atmospheric Correction (SMAC) (Proud et al. 2010). The atmospherically corrected brightness temperatures were converted to LST following the generalized split window proposed by Wan and Dozier (1996) for the Advanced Very High Resolution Radiometer (AVHRR) 
and MODIS, but adapted to SEVIRI response functions (Jimenez-Munoz and Sobrino 2008; Sobrino and Romaguera 2004). This data process was originally produced for (Nieto et al. 2011; Rasmussen et al. 2011; Stisen et al. 2007), and just applied in this study. For a closer data description we refer to these publications. Furthermore, a quality flag was produced for each LST value based on the cloud mask (PGE01) derived from the NWC SAF software, and quality flags related to clouds, unreliable data, sun-sensor geometry, and when the BRDF inversion failed (Proud et al. 2010; Proud et al. 2014).

\subsubsection{Fraction of vegetation cover}

Daily FVC derived from SEVIRI and distributed by the Land Surface Analysis Satellite Applications Facility (LSA SAF) were provided by Instituto Português do Mar e Atmosfera (IPMA), in the GLOBTEMP harmonised format $\left(0.05^{\circ}\right.$ spatial resolution) for 1 January 2010 to 31 December 2015 (GLOBTEMP 2014; Trigo et al. 2011). The FVC accounts for the amount of vegetation distributed in a horizontal perspective and is therefore an important structural property of a plant canopy, as well as a crucial proxy for studies relying on the partition between soil and vegetation contribution to surface emissivity and temperature. The daily FVC products are based on the k0 coefficient of a BRDF model for the red $(600 \mathrm{~nm})$, near infrared $(800 \mathrm{~nm})$ and shortwave infrared $(1600 \mathrm{~nm})$ channels, and is generated using an algorithm that relies on an optimised Spectral Mixture Analysis (SMA) technique (García-Haro et al. 2005). The products also include quality control information that were used to mask out pixels that were not reliable or relevant for this study (i.e. continental water, clouds, snow, unrealistic input ranges, or failure of the algorithm.

\subsubsection{Surface roughness and atmospheric forcing}

In order to analyse the homogeneity of surface properties and atmospheric forcing in relation to the use of TVDI, we downloaded ERA 5 surface solar radiation downwards (SSRD; $\mathrm{J} \mathrm{m}^{-2}$; accumulated at a 3-hour temporal resolution), forecast surface roughness (FSR; m; instantaneous at 12-hour 
temporal resolution), total column water vapour (TCWV; $\mathrm{kg} \mathrm{m}^{-2}$; instantaneous at 12-hour temporal resolution), wind speed at $100 \mathrm{~m}$ height (WS; $\mathrm{m} \mathrm{s}^{-1}$; $\mathrm{u}$ and $\mathrm{v}$ wind components instantaneous at 12hour temporal resolution), and air temperature at $975 \mathrm{hPa}$ level $\left(\mathrm{T}_{\text {air }} ; \mathrm{K}\right.$; instantaneous at 12 -hour temporal resolution)) with a spatial resolution of $0.1^{\circ} \times 0.1^{\circ}$ (interpolated using a bilinear method from $31 \times 31 \mathrm{~km}$ spatial resolution) from 1 January 2010-31 December 2015 from the European Centre for Medium-Range Weather Forecasts (ECMWF 2017). Collected WS and $\mathrm{T}_{\text {air }}$ represents conditions from above the blending height, since near surface variability in these parameters is driven by local meteorological conditions and is therefore allowed to be heterogeneous at the scale required for the triangular shape to take form. SSRD was converted to $\mathrm{W} \mathrm{m}^{-2}$ and all variables were averaged to daily values.

\subsubsection{In situ soil moisture}

In order to validate the disaggregation methodology we collected available in situ measurements of SM from eight sites within ISMN (Figure 2) (ISMN 2016). Available sites in West Africa with data 2010-2015 were from the AMMA-Catch (Niger and Benin sites) and Dahra (Senegal site) network: Banizoumbou (Niger; $\left.13.53{ }^{\circ} \mathrm{N} 2.66^{\circ} \mathrm{E}\right)$, Belefoungou-Mid (Benin; $\left.9.80^{\circ} \mathrm{N} \mathrm{1.71}{ }^{\circ} \mathrm{E}\right)$, BelefoungouTop (Benin; $\left.9.79^{\circ} \mathrm{N} 1.71^{\circ} \mathrm{E}\right)$, Dahra (Senegal; $\left.15.40{ }^{\circ} \mathrm{N} 15.43^{\circ} \mathrm{E}\right)$, Nalohou-Mid (Benin; $9.75^{\circ} \mathrm{N}$ $1.61^{\circ} \mathrm{E}$ ), Nalohou-Top (Benin; $9.74^{\circ} \mathrm{N} 1.61^{\circ} \mathrm{E}$ ), Tondikiboro (Niger; $\left.13.55^{\circ} \mathrm{N} 2.67^{\circ} \mathrm{E}\right)$ and Wankama (Niger; $13.65^{\circ} \mathrm{N} 2.63^{\circ} \mathrm{E}$ ). In situ $\mathrm{SM}$ was collected using vertical sampling at all these sites to capture the rooting zone soil profile. For the best possible intercomparison with the SMOS SM soil depth (average 0-5 cm), we only used data collected at the shallowest depths $(0.05 \mathrm{~m}$ depth for all sites but Nalohou-mid, where the shallowest depth was $0.10 \mathrm{~m}$ ). The two locations of Belefoungou and Nalohou were averaged before the analysis. 
The Niger and Senegal sites are located in the Sahel region characterised by a short rainy season between June and October. The Dahra field site and the Niger region receives around 400mm and $500 \mathrm{~mm}$ of rain, respectively (Louvet et al. 2015; Tagesson et al. 2015). The vegetation of the Niger sites are typical for cultivated areas of the Sahel, whereas the Dahra site is composed of open woody savannah (Louvet et al. 2015; Tagesson et al. 2016). The Benin sites are located further south in the Soudanian climate zone with an annual precipitation of $\sim 1300 \mathrm{~mm}$ (Louvet et al. 2015). These sites are thereby characterised by significantly denser vegetation, and woody savannah and tropical forest are typical of these sites (Louvet et al. 2015).

The in situ SM observations are from low density networks consisting of one or two sites per pixel which introduces an uncertainty in the representativeness of the sites in relation to the validation of the SM products (Peng et al. 2017). However, sensors at these sites were installed specifically for satellite product evaluation, hence the location of the sites were chosen to be representative for the larger area, and they have previously been used for various satellite product assessments. The in situ SM measurements are thereby considered representative for the wider area and applicable in a validation of large-scale satellite based SM estimates.

\subsection{Data analysis}

\subsubsection{Temperature and Vegetation Dryness Index (TVDI) as soil moisture proxy}

The TVDI was developed by Price (1990) and later improved notably by Sandholt et al. (2002) and Stisen et al. (2008). It has been widely used for assessing SM and evapotranspiration (Garcia et al. 2014; Han et al. 2010; Jiang et al. 2008; Li et al. 2010; Li et al. 2008; Mallick et al. 2009; Patel et al. 2009; Wang et al. 2004). Several methodological refinements were applied in this study as compared to previous approaches to make it applicable for SMOS disaggregation at the sub-continental scale: 
(1) The dTS was used as a substitute for LST as it was demonstrated to be a strong proxy for sensible heat fluxes, thereby improving the TVDI estimates as compared to those based on single (hourly or daily) LST (Stisen et al. 2008). The morning rise temperature was calculated as the change (i.e. slope coefficient $\left.\left({ }^{\circ} \mathrm{C} \mathrm{h}^{-1}\right)\right)$ in LST between sunrise and noon. A median Theil-Sen procedure was applied since it is known to be robust against non-normality, heteroscedasticity, and temporal autocorrelation (Alcaraz-Segura et al. 2010; Hirsch and Slack 1984; Vanbelle and Hughes 1984) and it is suggested for studies of trends based on time series of data (de Beurs and Henebry 2005). Furthermore, it is resistant to outliers and therefore suitable for assessing the rate of change in short or noisy time-series (Eastman et al. 2009). In order to minimise cloud contamination and erroneous data in the dTS and TVDI calculations, we filtered the FVC and LST data based on provided quality flags. We also excluded all dTS pixels using the following criteria: 1) temporal range of daily time-series $<4$ hours; 2) sample size used in the fit $<5$ cases; 3) dTS $>10{ }^{\circ} \mathrm{C} \mathrm{h}^{-1}$ and $<0{ }^{\circ} \mathrm{C} \mathrm{h}^{-1}$; and 4) poor LST vs time fit $(\mathrm{r}<0.70)$. Criteria 1 ensured that dTS was not calculated for pixels with clustered unfiltered data (i.e. only available for a short window of time during the day). Criteria 2 was set in order to ensure a sufficient number of observations. Criteria 3 and 4 were set to filter out observations with residual clouds.

(2) We used the algorithm proposed by Tang et al. (2010) to estimate the dry edge (LST max $_{\text {in }}$ equation 1) due to its low sensitivity to outliers (cloud residuals). In order to determine the upper edge of the triangle, we divided the dTS-FVC triangular space into bins with a FVC size of $2.5 \%$. Each bin was separated into 5 subintervals and the maximum dTS of each subinterval was extracted. All subinterval maximum dTS $<$ the average $\left(\mathrm{dTS}_{\text {sub_mean }}\right)$ minus one standard deviation $(\delta)$ of these 5 subinterval maximum dTS were removed and a new maximum dTS was calculated and used as the maximum for that specific bin. An ordinary least square linear regression was fitted through the remaining maximum dTS values and their corresponding FVC bins and used as the dry edge. These 
were the main steps in the algorithm; for a closer description we refer to Tang et al. (2010). The implementation of the algorithm was slightly modified compared to the original Tang et al. (2010) algorithm in that all bins to the left of the triangular maximum dTS and all dTS lower than wet edge (see below) were removed before the fitting.

(3) The wet edge (LST $\min$ in equation 1) was calculated as the median of the $10^{\text {th }}$ percentile dTS of the points included in the ten $2.5 \% \mathrm{FVC}$ bins with highest FVC values. The $10^{\text {th }}$ percentile was used instead of absolute minimum as it is less sensitive to outliers and therefore provides a more robust assessment of the wet edge.

(4) The study region was separated into different tiles. The size of the tiles (i.e. the number of SEVIRI pixels considered to adjust the dTS-FVC triangle for a given SMOS pixel) was set in such way that it strictly coincided in location and number with a multiple of the SMOS pixel resolution. This ensured that the information on spatial heterogeneity within a given SMOS pixel will be based on TVDI estimates that were derived from the same triangle adjustment. In this way, a SMOS pixel never over-lapped two different TVDI tiles, thereby maximizing the accuracy of the downscaling. A tile size of $105 \times 105$ SEVIRI pixels was selected for the final SMOS disaggregation (see results section).

(5) Furthermore the TVDI values were excluded based on quality of the dry edge fit ( $r>-0.7)$, dry edge intercept values $>15$ and $<0$, number of bins for estimating the dry edge $<5$, total number of points in triangle $<500$, FVC range $<0.3$. These filtering criteria excluded entire $105 \times 105$ pixelstiles. With these criteria we aimed at ensuring the comparability and temporal consistency of the data, having representative points over a large enough range of FVC (FVC range and number of bins), excluding TVDI estimates influenced by possible residual clouds (dry edge intercept range and fit), as well as having enough pixels to calculate the edges of the triangle and removal of those dates in 
which the cloud mask reduces the number of good quality pixels available for edge definition (total number of points and dry edge fit).

\subsubsection{Fulfilment of the preconditions of spatial dimensions and homogeneity}

Surface properties (FSR) and atmospheric forcing (SSRD, TCWV, WS, $\mathrm{T}_{\text {air }}$ ) should be homogenous within the triangular space for the dTS variability to accurately reflect SM variation. To test for homogeneous surface properties and atmospheric forcing within different sized tiles, we ran a threestep procedure. Firstly, FSR, SSRD, TCWV, WS, and $\mathrm{T}_{\text {air }}$ data were filtered based on the criteria described under point 1 in subsection 2.3.1. Secondly, we estimated the dynamic range of daily averages of FSR, SSRD, TCWV, WS, and $\mathrm{T}_{\text {air }}$ by taking the difference between the $95^{\text {th }}$ and the $5^{\text {th }}$ percentile for different tile sizes covering the Dahra and the Nalohou field sites. These 2 sites were assumed to be representative for the dry and wet parts of the study area, respectively. The $95^{\text {th }}$ and the $5^{\text {th }}$ percentile were used to avoid influence from outliers. The analysis of data range as a function of tile sizes started from $1 \times 1$ SEVIRI pixels with an increment of 1 pixels up until $200 \times 200$ SEVIRI pixels. Finally, percentiles (from 1 to the $100^{\text {th }}$ in steps of 1) from the full time-series were calculated for each analysed tile size. This was done to analyse the fraction of the time series affected by heterogeneity in FSR, SSRD, TCWV, WS, and $\mathrm{T}_{\text {air }}$ for the different tile sizes tested.

Thereafter, to test the fulfilment of the stated precondition that the spatial dimensions was large enough to capture a sufficient amount of dTS-FVC cases for the triangular shape to take form, we ran the TVDI analysis for the Dahra and the Nalohou field sites using different tile sizes. The analysis started from $5 \times 5$ SMOS pixels $(35 \times 35$ SEVIRI pixels $)$ with an increment of 5 SMOS pixels to $25 \times 25$ SMOS pixels $(175 \times 175$ SEVIRI pixels). The forming of the triangular shape are dependent on a sufficient number of points included in the triangle, the quality of the dry edge (r), and the dynamic 
355

356

357

358

359

360

361

$362 \quad \operatorname{TVDI}_{\mathrm{j}, \mathrm{t}}=\frac{\overline{\mathrm{TVDI}_{\mathrm{j}}}}{\overline{\langle\mathrm{TVDI}\rangle_{105}}}\left\langle\mathrm{TVDI}_{\mathrm{t}}\right\rangle_{105}$

363

364

365

366

367

368

369

370

371

372

373

374

375

376

\subsubsection{Gap-filling of TVDI} and FVC data). relationship is expressed as:

range in FVC. To analyse the effect of tile size we estimated percentiles (from 1 to the $100^{\text {th }}$ in steps of 1) of these parameters from the full time-series for each tile size analysed.

The calculated time-series of TVDI was gap-filled using two different approaches: (1) the excluded $105 \times 105$ SEVIRI pixels-tiles were filled by using the non-filtered tile nearest in time. This secures gap-filling of the tiles excluded based on the TVDI statistics according section 2.3.1 above. (2) Remaining excluded pixels were filled using long-term average calculated as follow:

where TVDI $\mathrm{jt}_{\mathrm{t}}$ is the TVDI at pixel (j) in a specific point in time (t) which is needing to be gap-filled; $\overline{\mathrm{TVDI}_{\mathrm{j}}}$ is the TVDI for the pixel (j) averaged for the entire time-series; $\left\langle\mathrm{TVDI}_{\mathrm{t}}\right\rangle_{105}$ is the TVDI averaged for the $105 \times 105$ pixels-tile for the point in time which needs to be gap-filled; and $\overline{\langle\mathrm{TVDI}\rangle_{105}}$ is the TVDI averaged for the $105 \times 105$ pixels-tile and averaged for the entire time series. This second gapfilling procedure fills pixels that were excluded based on quality flags of the input data (excluded dTS

\subsubsection{Disaggregation methodology}

The SMOS SM was disaggregated following the methodology in Merlin et al. (2012) where spatial heterogeneity in surface SM within the SMOS pixel is linked with a heterogeneity in the soil evaporative efficiency (SEE). Merlin et al. (2012) chose SEE as high resolution data within the disaggregation methodology because of the strong correlation to surface SM (Anderson et al. 2007) and its stability during daytime under clear skies (Crago and Brutsaert 1996). The disaggregation 
$377 \quad \mathrm{SM}_{\text {disaggregated }}=\mathrm{SM}_{\mathrm{SMOS}}+\frac{\partial \mathrm{SM}_{\text {model }}}{\partial \mathrm{SEE}}\left(\mathrm{SEE}_{\mathrm{SEVIRI}}-\left\langle\mathrm{SEE}_{\mathrm{SEVIRI}}\right\rangle_{\mathrm{SMOS}}\right)$

378 where $\mathrm{SM}_{\text {disaggregated }}$ is the high-resolution SM product disaggregated from the original SMOS data

$379\left(\mathrm{SM}_{\mathrm{SMOS}}\right) ; \frac{\partial \mathrm{SM}_{\text {model }}}{\partial \mathrm{SEE}}$ is the partial derivative of modelled SM on SEE; SEE $\mathrm{SEVIRI}_{\text {is high-resolution }}$ 380 SEE based on SEVIRI input data; and $\left\langle\mathrm{SEE}_{\text {SEVIRI }}\right\rangle_{\text {SMOS }}$ is SEE averaged at SMOS scale.

381 Merlin et al. (2010) tested the accuracy and robustness of the aggregation methodology using different 382 formulations for modelling SEE. They concluded that the formulation of Noilhan and Planton (1989) 383 was the most applicable when conditions for soil properties were unknown:

$384 \quad \mathrm{SEE}_{\text {model }}=\frac{1}{2}-\frac{1}{2} \cos \left(\pi \times \frac{\mathrm{SM}}{\mathrm{SM}_{\mathrm{p}}}\right)$

385 where $\mathrm{SEE}_{\text {model }}$ is modelled $\mathrm{SEE}$, and $\mathrm{SM}_{\mathrm{p}}$ is a soil parameter in $\mathrm{SM}$ unit. In Merlin et al. (2012) $\mathrm{SM}_{\mathrm{p}}$ 386 was estimated by inverting Equation 4 at SMOS resolution:

$387 \quad \mathrm{SM}_{\mathrm{p}}=\frac{\pi \times \mathrm{SM}_{\mathrm{SMOS}}}{\arccos \left(1-2\left\langle\mathrm{SEE}_{\mathrm{SEVIRI}}\right\rangle_{\mathrm{SMOS}}\right)}$

388 By inverting equation 5, we got a model for estimating SM based on SEE:

$389 \quad \mathrm{SM}_{\text {model }}=\frac{\mathrm{SM}_{\mathrm{p}}}{\pi} \arccos (1-2 \mathrm{SEE})$

390 Then, by taking the partial derivative of SM on SEE in equation 6, we get:

$391 \quad \frac{\partial \mathrm{SM}_{\text {model }}}{\partial \mathrm{SE}}=\frac{2\left(\frac{\mathrm{SM}}{\pi}\right)}{\sqrt{1-(1-2 \mathrm{SE})^{2}}}$

392 Merlin et al. (2012) showed a linear relationship between SEE and surface soil temperature using a 393 physically based dual source energy budget model (Kustas and Norman 1999) and a synthetic data 394 set. Given that TVDI was based on soil thermal inertia (dTS), it should be a strong proxy of the non395 evaporative fraction, and SEE then equals (1-TVDI). For a description of the mathematical derivation 
of equations 5 and 7; we refer to Appendix A. For a mathematical derivation showing that (1-TVDI) equals SEE in the way it is implemented in the DisPATCH methodology, we refer to Appendix B. Finally, equation 7 was inserted into equation 3 and by setting SEE to (1-TVDI), we obtained a disaggregation model directly based on TVDI.

$\mathrm{SM}_{\text {disaggregated }}=\mathrm{SM}_{\mathrm{SMOS}}+\frac{2\left(\frac{\mathrm{SM}_{\mathrm{SMOS}}}{\arccos \left(1-2\langle(1-\mathrm{TVD})\rangle_{\text {SMOS }}\right)}\right)}{\sqrt{1-(1-2(1-\mathrm{TV}))^{2}}}\left((1-\mathrm{TVDI})-\langle(1-\mathrm{TVDI})\rangle_{\mathrm{SMOS}}\right)$

\subsubsection{Sensitivity of TVDI and disaggregated SMOS soil moisture to input data}

We analysed the sensitivity of TVDI to its input parameters using a synthetic data set with dTS varying from 0 to 10 , and FVC varying from 0 to 1.0. TVDI was estimated by setting the wet edge to

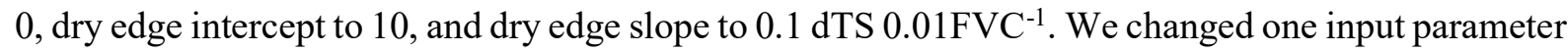
at the time with $\pm 10 \%$ of the total range included in the triangle at steps of $0.1 \%$ and recalculated TVDI. The input parameters changed included dTS $\left( \pm 1^{\circ} \mathrm{C}\right)$, FVC $( \pm 0.10)$, wet edge $\left( \pm 1^{\circ} \mathrm{C}\right)$, dry edge intercept $\left( \pm 1^{\circ} \mathrm{C}\right)$, and dry edge slope $\left( \pm 0.1^{\circ} \mathrm{C} 0.01 \mathrm{FVC}^{-1}\right)$. The sensitivity of TVDI to the parameters was quantified by fitting an ordinary least square linear regression between recalculated TVDI and $\%$ error for each dTS-FVC combination.

To quantify the sensitivity of disaggregated SMOS SM to errors in TVDI, we disaggregated SMOS SM using equation 8 with SMOS SM varying from 0 to $100 \%$, TVDI varying from 0.0 to 1.0 , and mean TVDI for each SMOS pixel (〈(TVDI) $\left.\rangle_{\text {SMOS }}\right)$ set to $0.25,0.50$ and 0.75 . We changed TVDI with \pm 0.1 at steps of 0.01 and repeated the disaggregation procedure. The sensitivity of disaggregated SMOS SM to errors in TVDI was quantified by fitting an ordinary least square linear regression between disaggregated SMOS SM and the TVDI error for each SMOS SM, TVDI, and $\left(\langle(\text { TVDI })\rangle_{\text {SMOS }}\right)$ combination.

\subsubsection{Evaluation of soil moisture products}


We evaluated both the original and the disaggregated SMOS SM using the in situ based SM data sets from ISMN as independent data. The agreements between SMOS based SM and the in situ SM were quantified as the root mean square error (RMSE), the product-in situ ratio, and by goodness-of-fit when an ordinary least-square linear regression was fitted between SMOS based SM and daily in situ SM estimates. Spatial patterns of the disaggregated SMOS SM over West Africa were also evaluated for a specific case of extreme SM conditions (i.e. drought and flood). Monthly anomalies of SM were estimated by subtracting the 2010-2015 climatology from the monthly average SM. July to September (JAS) 2012 was selected as test case because both heavy rainfall events and dry conditions corresponding to the ending of the long-lasting drought of 2011-2012 were registered during that period (de Robert 2012; FEWSNET 2012a, b). Beside JAS also corresponds to growing season months in most West Africa, which makes it an interesting case for evaluating potential monitoring products of hydrological extremes from a food security and disaster management point of view.

\section{Results}

\subsection{Tile size selection and spatio-temporal variability of TVDI}

The dynamic range of the parameters affecting available energy within the triangular space differs slightly in their relation to tile size. The dynamic range in FSR was relatively stable over a large spectrum of tile sizes. It was found to increase rapidly to a value close to the maximum where after it remained stable (at $\sim 0.5$ and $\sim 1.6 \mathrm{~m}$ for Dahra and Nalohou, respectively) up to a tile size of $\sim$ 160×160 SEVIRI pixels (Figure 3 a). The dynamic range in SSRD, TCWV, WS and $\mathrm{T}_{\text {air }}$ increased more continuously with tile size (Figure $3 \mathrm{~b}$ and $3 \mathrm{c}$ ). Up until a tile size of $100 \times 100$ SEVIRI pixels, daily averaged SSRD was $<30 \mathrm{~W} \mathrm{~m}^{-2}$ for $\sim 85 \%$ and $\sim 75 \%$ of the time series, and daily averaged WS was $<6 \mathrm{~m} \mathrm{~s}^{-1}$ for $\sim 80 \%$ and $\sim 98 \%$ of the time series for Dahra and Nalohou, respectively, (Figure $3 \mathrm{~b}$ 
and 3d). Total colomn water vapour (TCWV) and $\mathrm{T}_{\text {air }}$ were more strongly affected by tile size with a 441 larger fraction of the time series having a large dynamic range (Figure $3 \mathrm{c}$ and $3 \mathrm{e}$ ).

442 Both the sample size and the FVC range increased strongly with tile size (Figure 4). Using the defined 443 filtering criteria for the sample size $(>500)$ it can be seen that $40 \%, 22 \%, 11 \%, 4 \%$, and $1 \%$ of the 444 time series for Nalohou and 26\%, 12\%,8\%,5\%, and 3\% of the time series for Dahra would be rejected 445 for the different tested tile sizes (with increased tile size order). Tile size is thereby a trade-off between 446 having a large enough sample size allowing for a sufficient amount of dTS-FVC cases, but keeping 447 it as small as possible not to induce uncertainty caused by heterogeneity in the available energy within 448 the triangular space. Reaching a sufficient number of points was challenging during the rainy season, 449 especially in the Southern parts of the study area due to the low number of eligible dTS/FVC pixels 450 (e.g. cloud-free data and good dTS fits) (Figure 5a). As a compromise, when enlarging the tile size 451 to $105 \times 105$ SEVIRI pixels, more pixels passed the filtering criteria (Figure 5c), and this tile size was 452 chosen for the final analysis. 

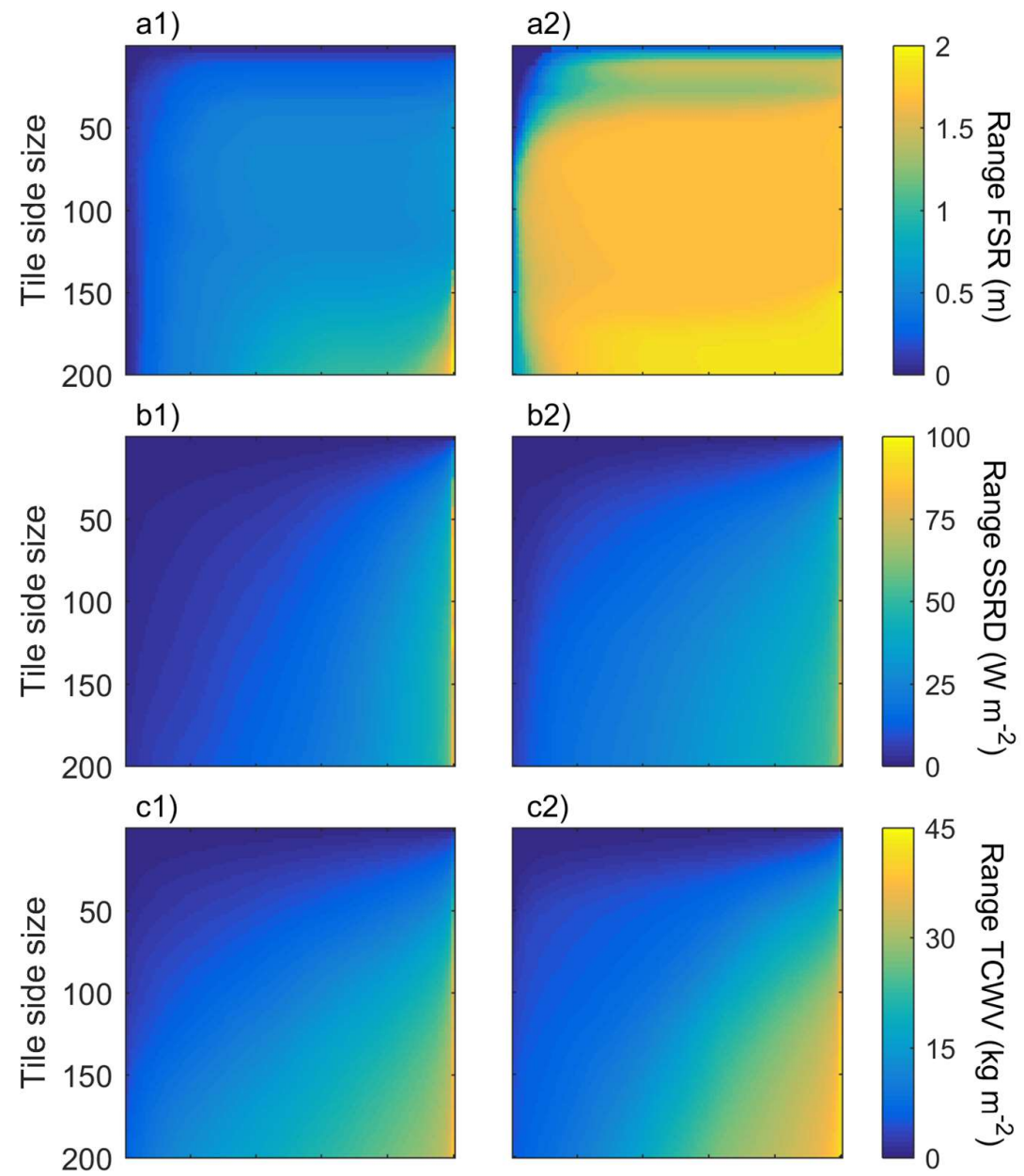

c2)
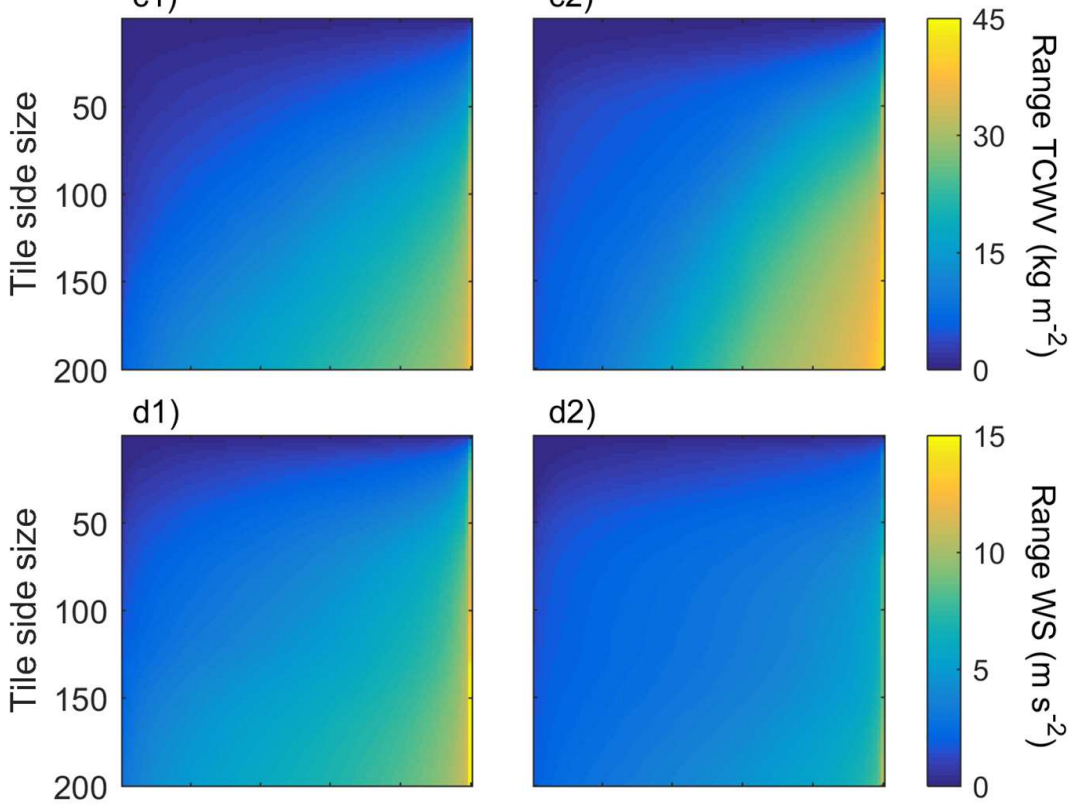

d2)
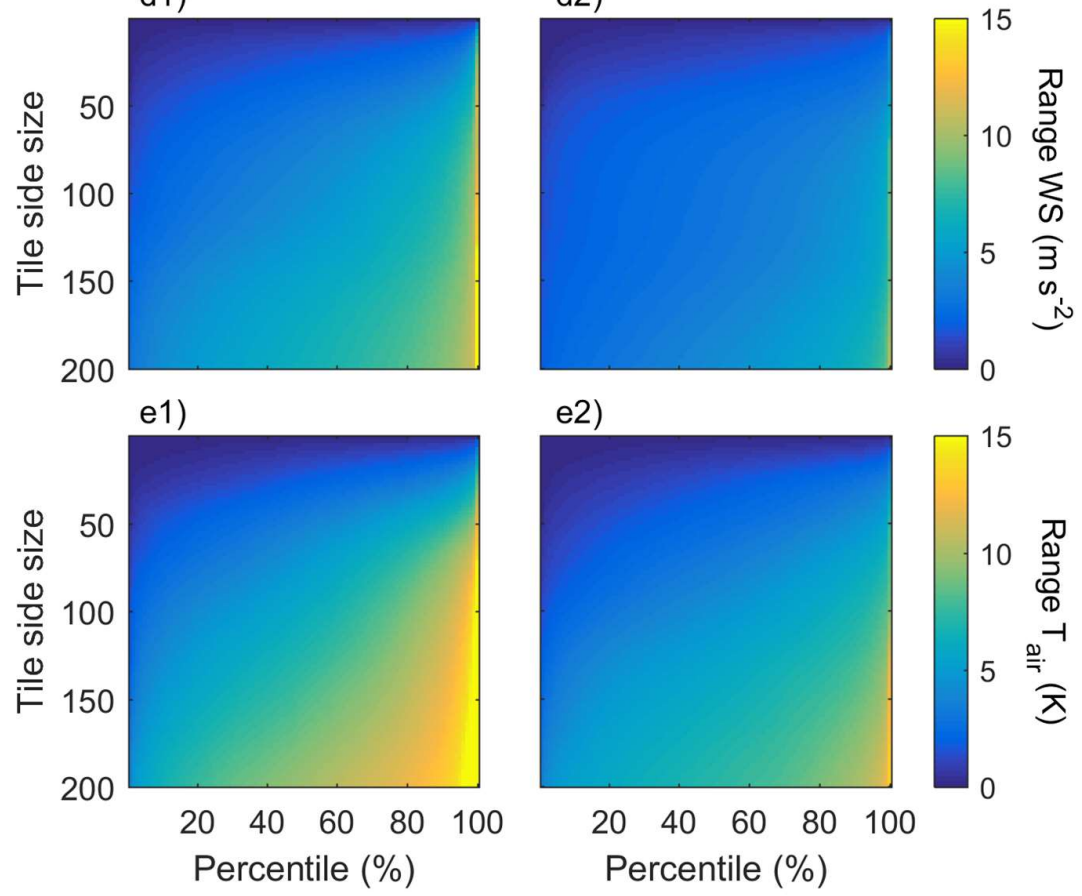
Figure 3. Dynamic range in surface properties and atmospheric forcing influencing the homogeneity of available energy within the triangular space. Influence of tile size (y-axis) on the percentiles of the time series (x-axis) of the dynamic range in daily averaged a) forecast surface roughness (FSR) (m); b), surface solar radiation downwards (SSRD) $\left(\mathrm{W} \mathrm{m}^{-2}\right)$; c) total column water vapour (TCWV) $(\mathrm{kg}$ $\left.\mathrm{m}^{-2}\right)$; d) wind speed at $100 \mathrm{~m}$ height (WS) $\left(\mathrm{m} \mathrm{s}^{-1}\right)$; and e) air temperature at the $975 \mathrm{hPa}$ level $\left(\mathrm{T}_{\text {air }}\right)$ (K) for 1) the Dahra and 2) the Nalohou field sites. The percentiles on the X-axis gives an indication of the fraction of the time series for a given tile size having a dynamic range smaller than the value shown by the colour. For the z-axis, dark blue indicates high homogeneity (i.e. small dynamic range) in surface properties or atmospheric forcing, whereas yellow indicates low homogeneity.
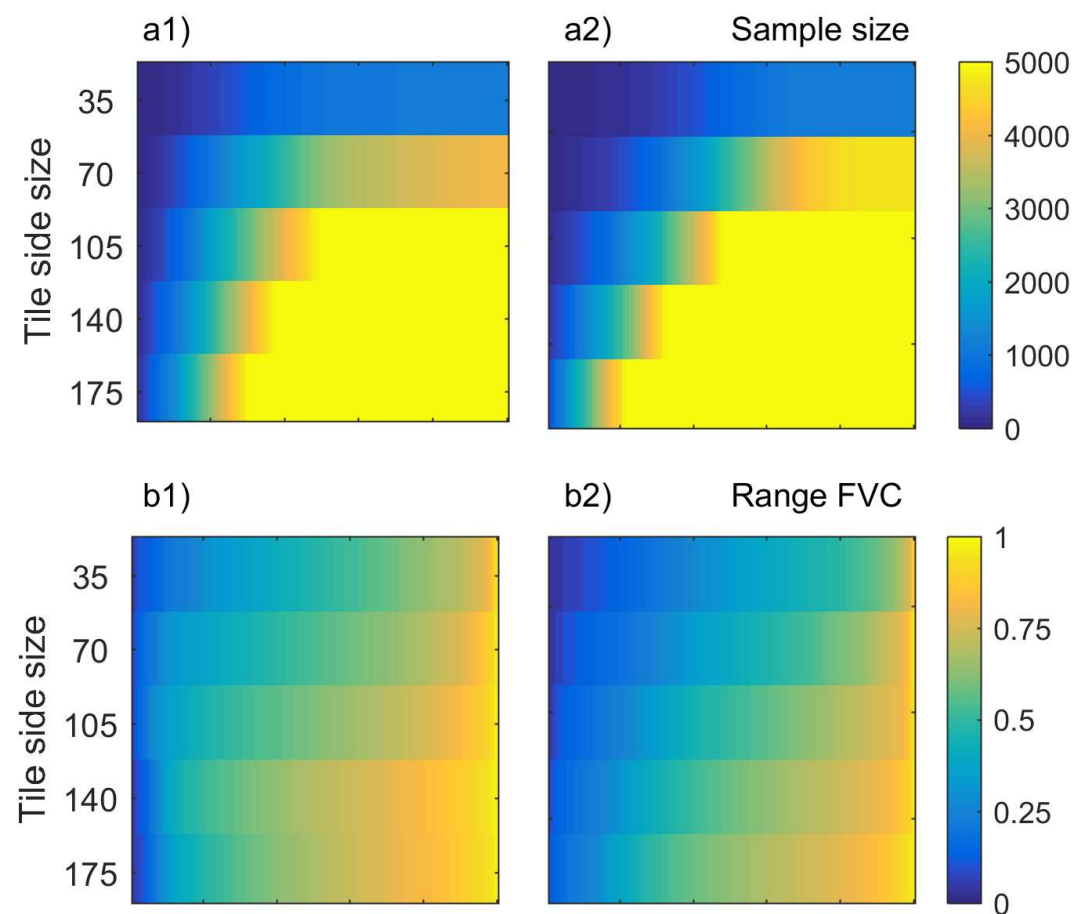

b2) Range FVC
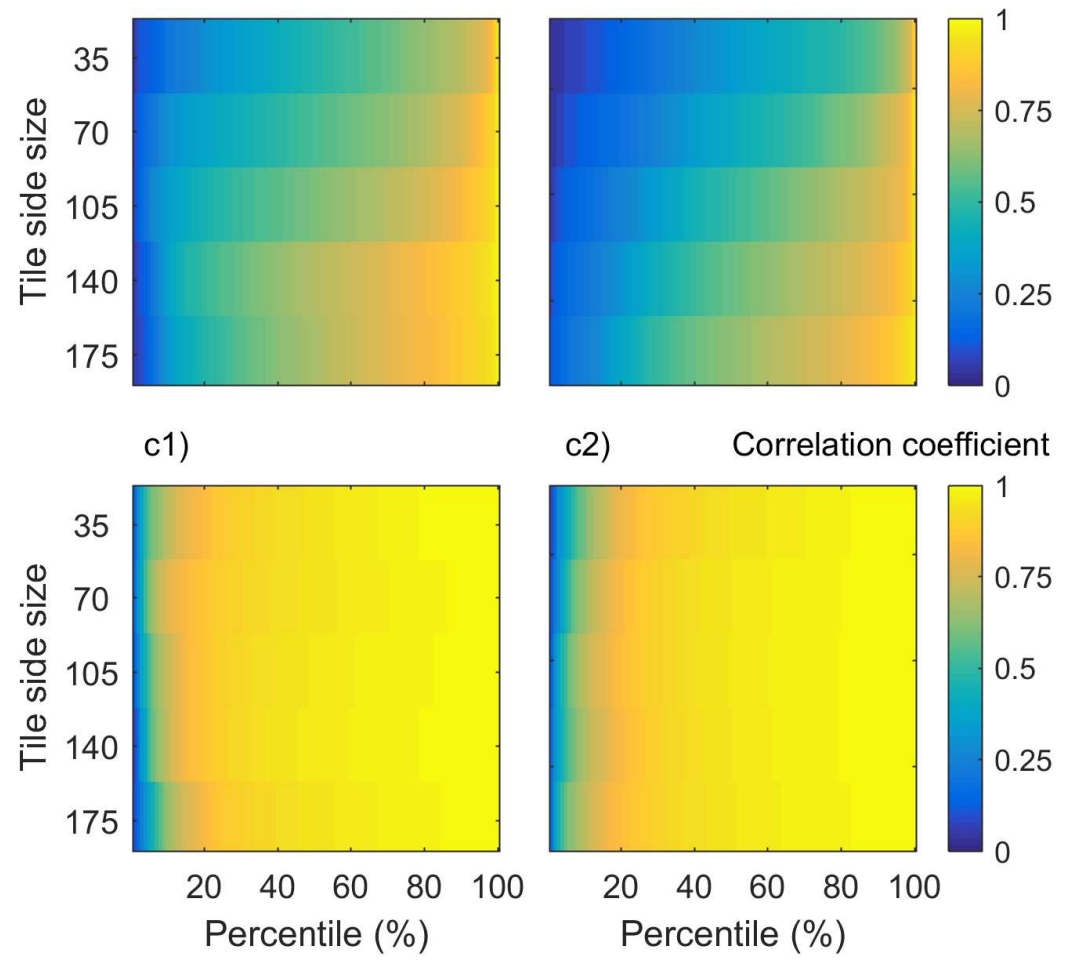
Figure 4. Influence of tile size (y-axis) on the percentiles of the time series (x-axis) of the parameters influencing the triangular shape. a) Number of points including in the triangle $(\mathrm{N})$; b) range in fraction of vegetation cover (FVC); and c) correlation coefficient of the dry edge slope (r) for 1) the Dahra and, 2) the Nalohou field sites. The percentiles on the x-axis gives an indication of the fraction of the time-series for a given tile size having a range smaller than the value shown by the colour.

It can be seen that the amount of unfiltered input data (dTS and FVC) increased substantially with latitude (Figure 5a); the further south the higher the fraction of cloud cover and an almost linear loss of data is observed southwards from $20^{\circ} \mathrm{N}$ (Figure 5c). The amount of data excluded based on TVDI tile statistics had the opposite pattern; at the border between the Sahel and the Sahara the FVC range required for the triangular shape to take form starts to be too low (around $15^{\circ} \mathrm{N}$ ) and above $17.5^{\circ} \mathrm{N}$ no TVDI retrievals are obtained (Figure 5c). As a result, the largest amount of eligible data for calculating TVDI was observed in the central part of the study area at $\sim 13.5^{\circ} \mathrm{N}$. In the spatial pattern of the average TVDI for the entire study period, clear borders between the different tiles can be seen (Figure 5d). However, when combining TVDI with SMOS SM using the disaggregation methodology, the blocky structure disappears and SM heterogeneity across the study area is revealed (Figure 5e; cf subsection 3.3 below). 

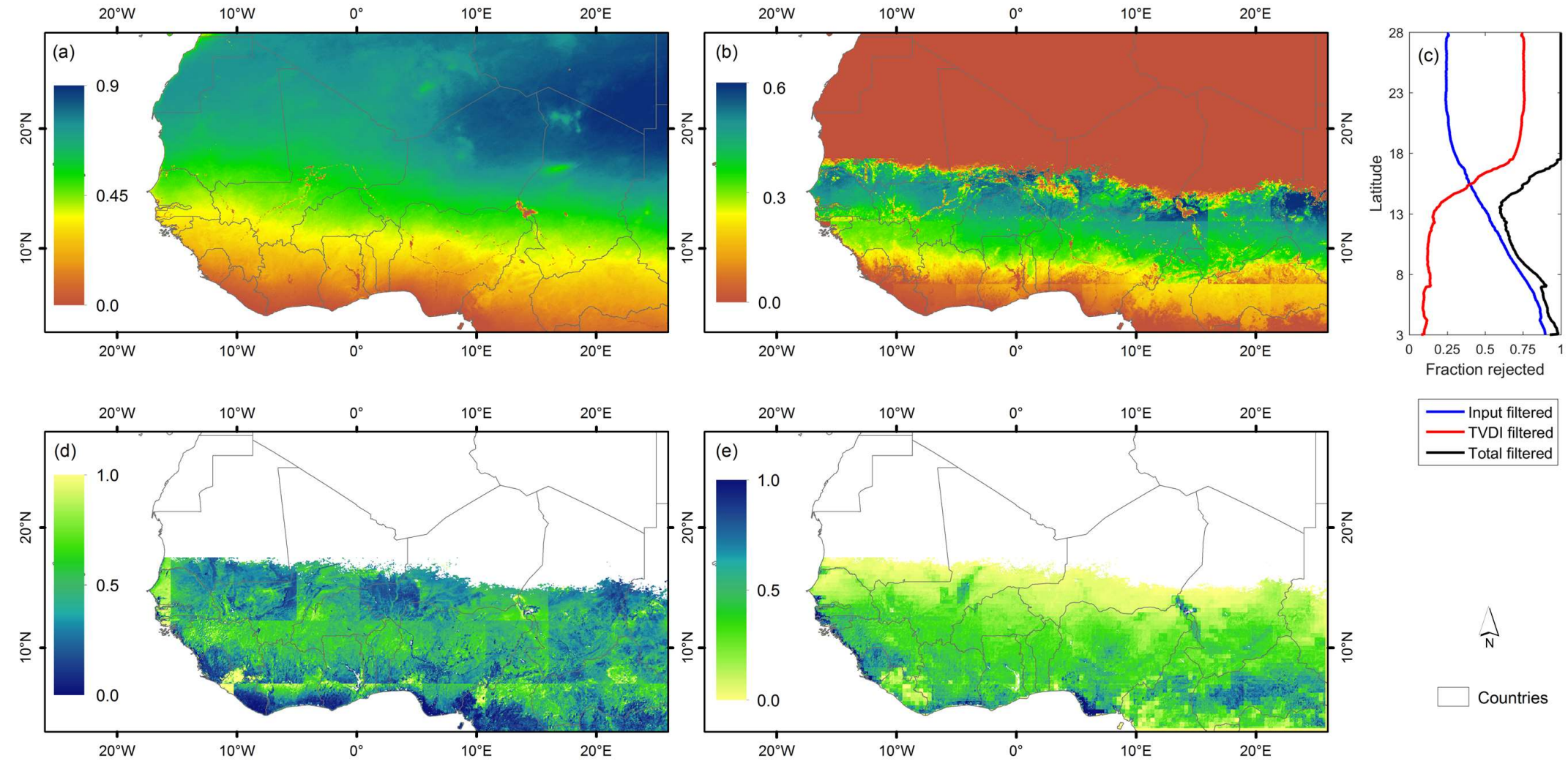

Figure 5. (a) Fraction of data coverage for the input data (dTS and FVC) used in the TVDI calculations; (b) fraction of data coverage for the TVDI calculations when TVDI was filtered based on both TVDI tile statistics and quality flags in input data. (c) Average data exclusion fraction depending on latitude; blue is the fraction of rejected input data, red is the fraction rejected in relation to the TVDI calculation, and black is the total rejected fraction. Included are also: (d) average TVDI for the entire study period; and (e) disaggregated SMOS SM averaged for the entire study period. 
490 Clear seasonality was observed in the FVC and dTS time series for the pixels covering the Dahra and 491 the Nalohou field sites (Figure 6a,b,) whereas TVDI did not exhibit any sign of seasonal patterns and 492 had a relatively large variability (Figure $6 \mathrm{~h}$ ). The FVC range observed in the adjustment window 493 varied a lot throughout the year at the semi-arid Sahelian site; even though no clear seasonality was 494 detected (Figure 6c1). For the southern humid Soudanian savanna site, FVC was also highly variable, 495 but with a clear seasonality decreasing the FVC range during the rainy season (Figure 6c2). This was 496 most likely caused by an increased vegetation cover throughout the tile during this part of the 497 year. The coefficient of determination $\left(R^{2}\right)$ of the dry edge fit remained high the entire year $(>0.75)$, 498 but a larger variability was observed during the rainy season (Figure 6e).

499 

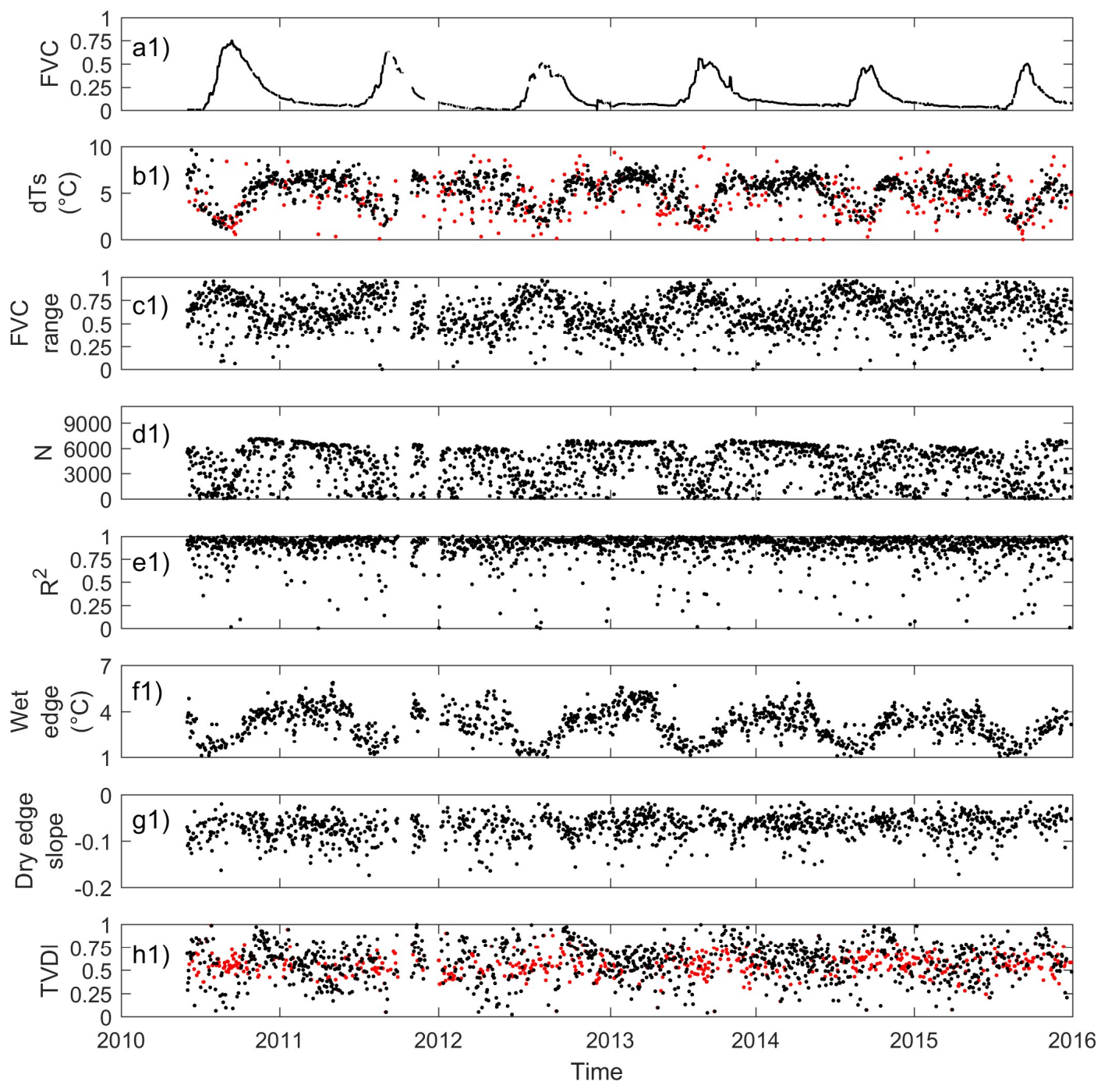

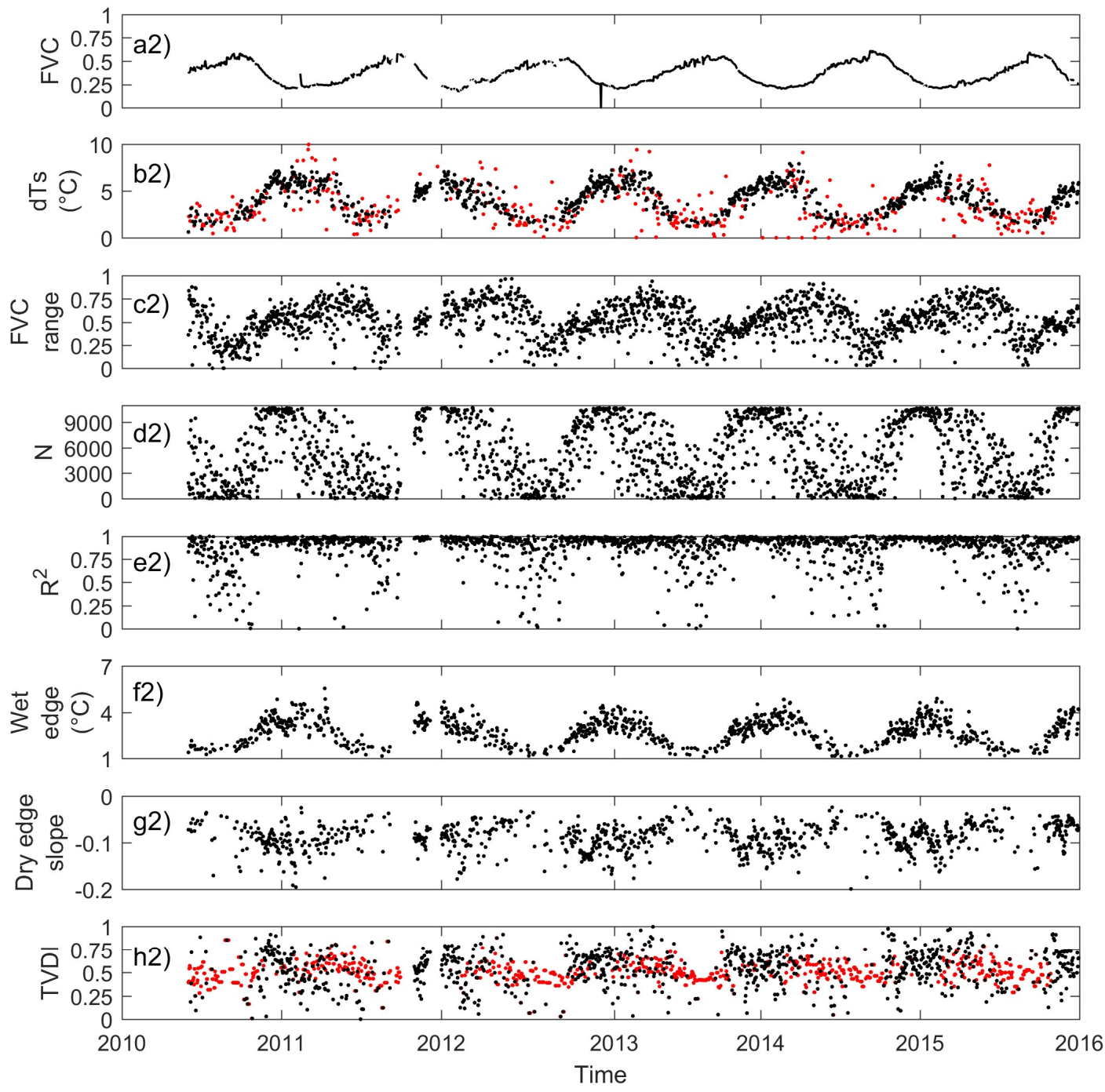

501

502

503

504

505

506

507

508

Figure 6. Time series of the input parameters, extracts from the TVDI calculation tiles, and final TVDI estimates for (1) Dahra and (2) Nalohou: (a,) fraction of vegetation cover (FVC); (b) unfiltered (red) and filtered (black) morning rise temperature (dTS); (c) range of FVC in the TVDI tiles; (d) total number of points included in the triangle $(\mathrm{N})$; (e) coefficient of determination $\left(\mathrm{R}^{2}\right)$ for the dry edge fit; (f) wet edge; and (g) dry edge slope. Included are also (h) filtered (black) and gap-filled (red) TVDI estimates (black).

\subsection{Sensitivity of TVDI and soil moisture to input parameters}


The sensitivity analysis of TVDI indicated that sensitivity is strongly dependent on the pixel location within the triangular space. Errors in the input parameters have a very strong impact on the estimated TVDI at the peak of the triangle (upper part of the FVC range) whereas TVDI is less affected close to the vertical catheter of the triangle (lower part of the FVC range) (Figure 7). The reason for this is the small dTS range at the peak of the triangle, resulting in a large sensitivity. An error in the input dTS data have the same impact throughout the entire TVDI range (Figure 7a). As expected, TVDI values close to the dry edge $(\mathrm{TVDI}=1.0)$ are more sensitive to errors in the $\mathrm{FVC}$, the dry edge slope and the dry edge intercept (Figure 7b-d) than TVDI values close to the wet edge (Figure 7e). The opposite is the case close to the wet edge $(\mathrm{TVDI}=0.0)$ where TVDI values are insensitive to errors in the above mentioned parameters (FVC, the dry edge slope and intercept) but more sensitive to an error in the wet edge.

For low SMOS SM values, disaggregated SM remain low throughout the entire TVDI range (Figure 8 a1-c1) and the disaggregation procedure is thereby rather insensitive to errors in TVDI for this SMOS SM region (Figure 8 a2-c2). However, as SMOS SM increases the range in disaggregated SM start to range from $0-100 \%$ (Figure 8 a1-c1), with implications for the sensitivity of the disaggregation procedure. The effect of a change in TVDI is strongest for combinations of low SMOS SM and low TVDI and high SMOS SM and high TVDI (seen in the colour change of Figure 8 a1- c1). For example, when $\langle(\text { TVDI })\rangle_{\text {SMOS }}$ is set to 0.75 disaggregated SM goes from 0 to $100 \%$ Vol with a TVDI change from 1.0 to 0.8 (Figure $8 \mathrm{c} 1$ ). This pattern is also visible in the sensitivity of disaggregated SMOS SM to TVDI (Figure 8c2). The most sensitive parts of the triangular space for the disaggregation procedure are thereby close to the wet and dry edges where TVDI approaches 0.0 and 1.0 , respectively. 

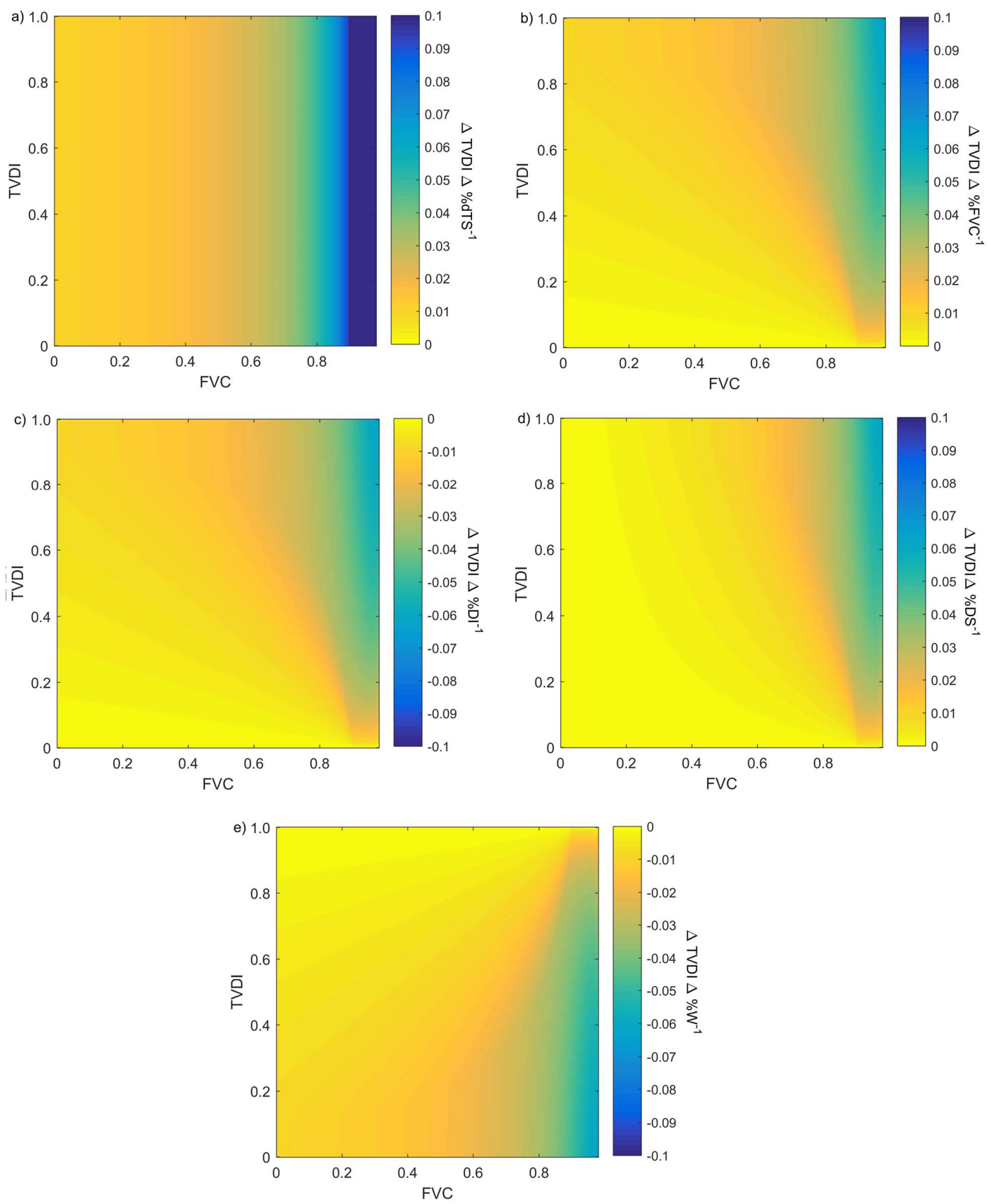

Figure 7. Sensitivity of TVDI to input data and equation parameters: a) morning rise temperature $\left(\mathrm{dTS} ;{ }^{\circ} \mathrm{C}\right)$; b) fraction of vegetation cover (FVC); c) dry edge intercept (DI); d) dry edge slope (DS); and e) wet edge (W). The $\%$ for the temperatures (dTS, DI, and W) and the FVC is a \% change in 
relation to the range of the triangle. During the analysis we changed one parameter at the time and the rest remained stable.
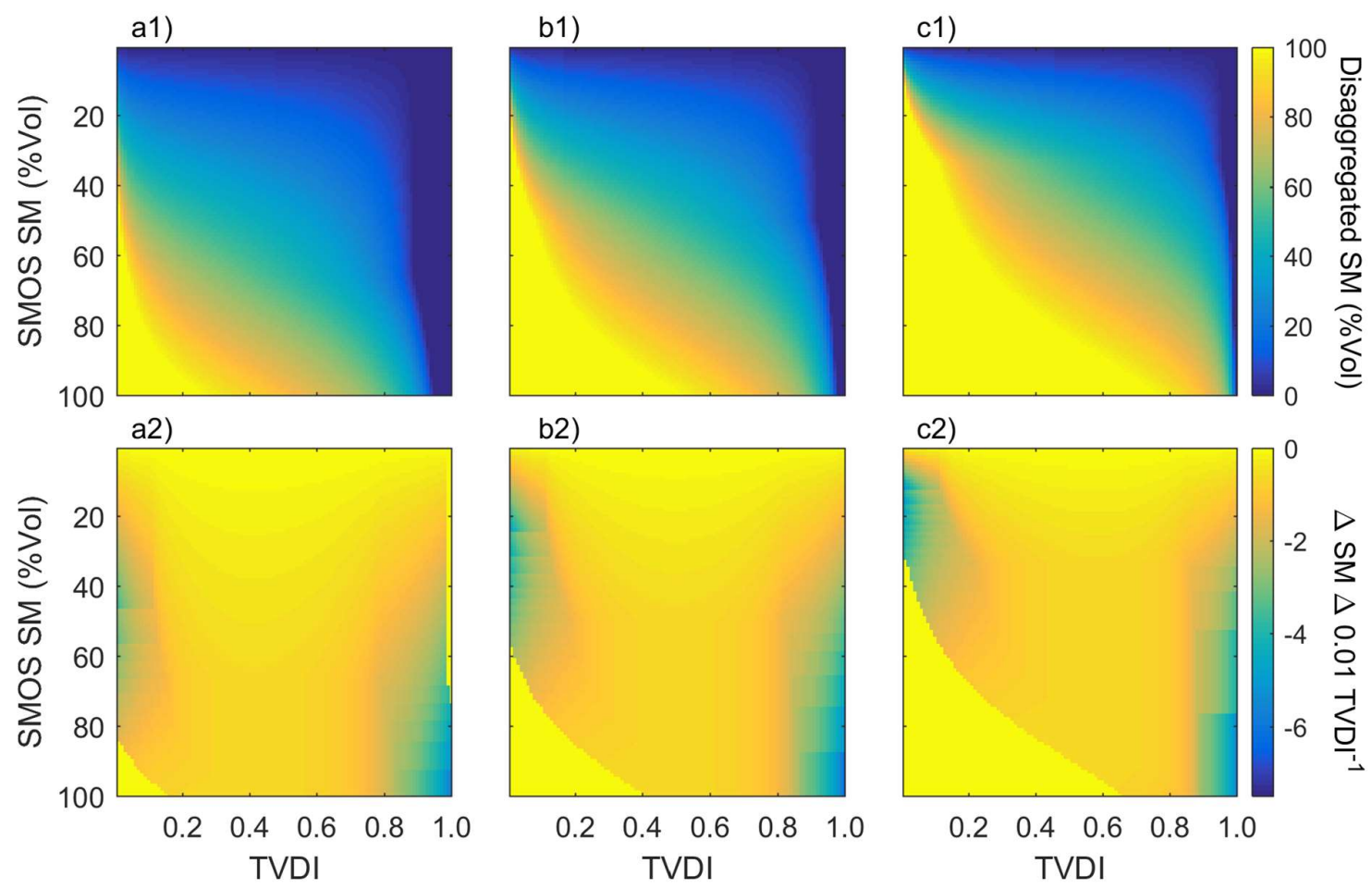

Figure 8. Sensitivity of disaggregated SMOS soil moisture (SM; \%Vol) to changes in TVDI. Average TVDI in equation 8 was set to a) 0.25 , b) 0.50 and c) 0.75 . First row (1) shows the actual disaggregated SM for each original SMOS SM -TVDI case and second row (2) shows the changes in disaggregated SM for each 0.01 error in TVDI for each SM -TVDI case.

\subsection{Evaluation of the SMOS soil moisture products}

The original SM product from SMOS generally describes the seasonal dynamics well for the 6 sites

(Figure 9). The SMOS SM were on average $8.41 \%$ Vol whereas in situ SM was on average $6.33 \%$ Vol and it can be seen that SMOS SM is overestimated at some of the sites (Belefoungou and Nalohou).

This overestimation generated a relatively high RMSE $(6.26 \% \mathrm{Vol})$ between SMOS SM and in situ SM (Table 1). The sites with the highest overestimation are located in the southern humid parts of the study area (Figure 9). The linear function fitted between SMOS SM and in situ SM also indicated a 
555 Table 1; slope: 1.26; intercept: 0.77; $\mathrm{R}^{2}$ : 0.73).
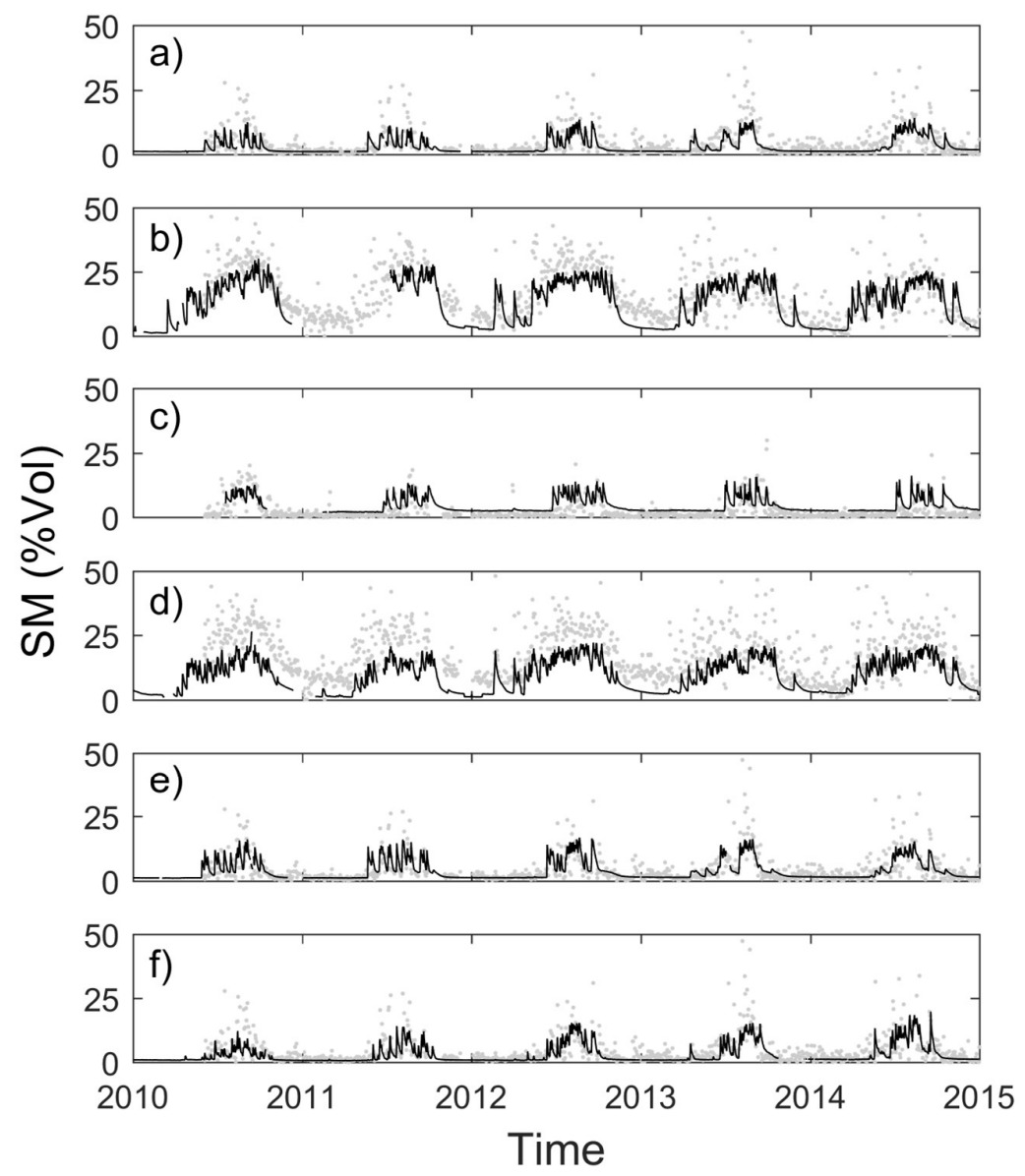

558 Figure 9. Time series of in situ measured soil moisture (SM (\%Vol)) (thin black line) and Soil 559 moisture and Ocean Salinity (SMOS) SM (grey dots) for: a) Banizoumbou; b) Belefoungou; c) Dahra; 560 d) Nalohou e) Tondikiboro; and f) Wankama. The location of the different sites is shown in Figure 2. 

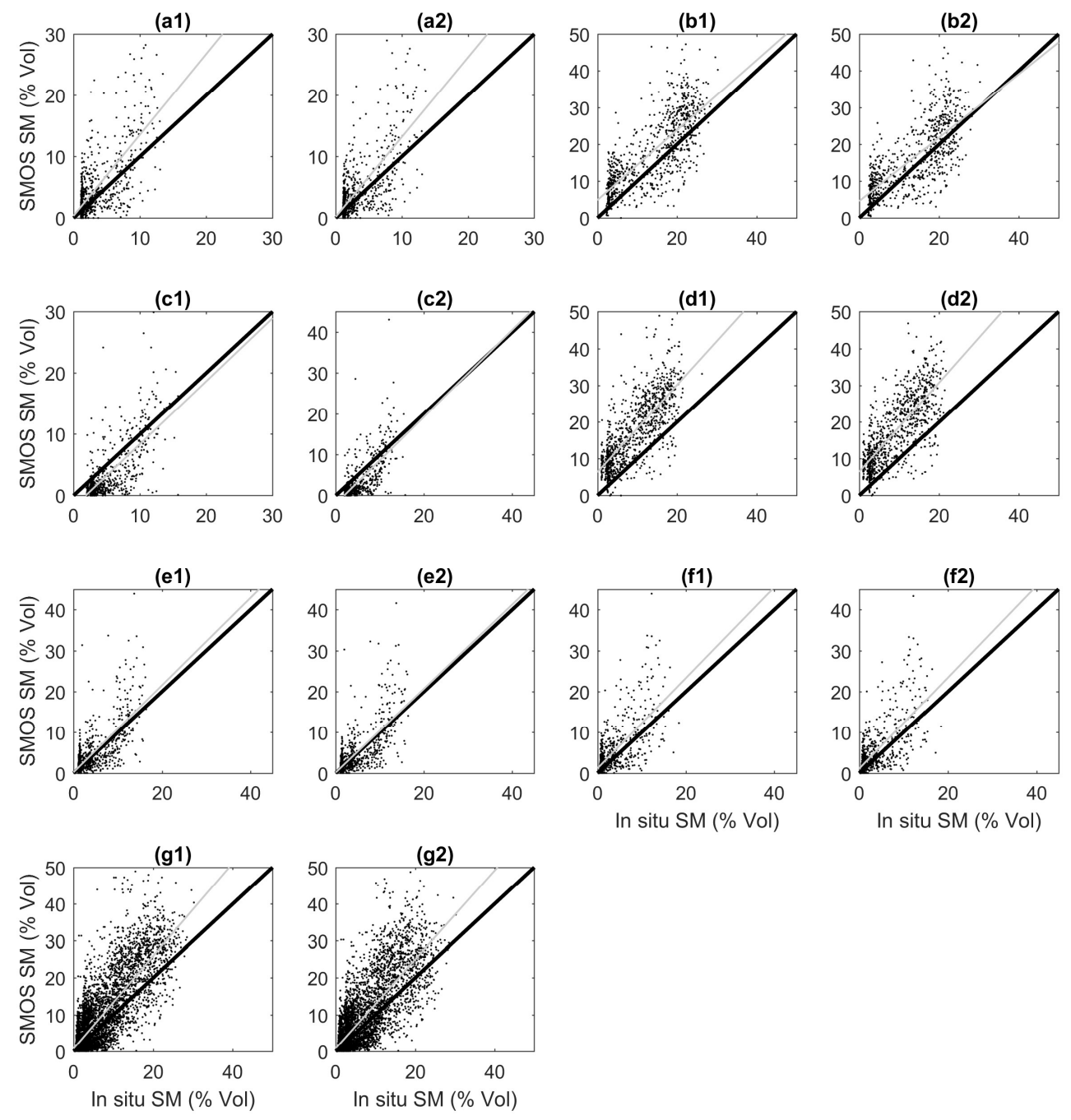

Figure 10. Relationship between in situ and both original (1) and disaggregated (2) Soil Moisture and Ocean Salinity (SMOS) soil moisture (SM; \%Vol) for the pixels used in the evaluation of the disaggregation methodology. The subplots are: a) Banizoumbou; b) Belefoungou; c) Dahra; d) Nalohou; e) Tondikiboro; f) Wankama; and g) all sites combined. The grey line is the ordinary least square linear regression and the black line is the one-to-one ratio. Statistics of the slopes are given in Table 1 . The location of the sites can be seen in figure 2 . 
573 Table 1. Comparative statistics for the in situ validation of the original SMOS and disaggregated SMOS soil moisture. The ratio was the 574 product-in-situ ratio and it was calculated as original and disaggregated SMOS SM divided by the in situ measurements. The analysis was 575 conducted for individual sites and with all data combined.

\begin{tabular}{|c|c|c|c|c|c|c|c|c|c|c|c|c|}
\hline \multirow[b]{2}{*}{ Validation site } & \multicolumn{6}{|c|}{ Original SMOS } & \multicolumn{6}{|c|}{ Disaggregated SMOS } \\
\hline & Slope & $\begin{array}{c}\text { Intercept } \\
\text { (\%Vol) }\end{array}$ & $\mathbf{R 2}$ & $\begin{array}{c}\text { Mean bias } \\
(\% \text { Vol })\end{array}$ & Ratio & $\begin{array}{l}\text { RMSE } \\
\text { (\%Vol) }\end{array}$ & Slope & $\begin{array}{c}\text { Intercept } \\
\text { (\%Vol) }\end{array}$ & $\mathbf{R 2}$ & $\begin{array}{c}\text { Mean bias } \\
\text { (\%Vol) }\end{array}$ & Ratio & $\begin{array}{l}\text { RMSE } \\
\text { (\%Vol) }\end{array}$ \\
\hline Banizoumbou (BAN) & 1.32 & 0.35 & 0.58 & -1.36 & 1.44 & 4.45 & 1.30 & 0.19 & 0.59 & -1.13 & 1.36 & 4.18 \\
\hline Belefoungou (BEL) & 0.95 & 4.87 & 0.71 & -4.19 & 1.25 & 7.81 & 0.86 & 4.57 & 0.67 & -2.77 & 1.10 & 6.93 \\
\hline Dahra (DAH) & 1.03 & -1.88 & 0.58 & 1.76 & 0.59 & 3.21 & 1.06 & -2.03 & 0.55 & 1.74 & 0.59 & 3.42 \\
\hline Nalohou (NAL) & 1.19 & 6.35 & 0.68 & -8.13 & 1.80 & 10.21 & 1.22 & 6.44 & 0.66 & -8.39 & 1.76 & 10.61 \\
\hline Tondikiboro (TON) & 1.07 & 0.22 & 0.61 & -0.49 & 1.13 & 4.03 & 1.03 & 0.17 & 0.61 & -0.28 & 1.07 & 3.87 \\
\hline Wankama (WAN) & 1.11 & 1.16 & 0.59 & -1.5 & 1.45 & 4.41 & 1.12 & 1.10 & 0.59 & -1.47 & 1.43 & 4.36 \\
\hline All & 1.26 & 0.77 & 0.73 & -2.38 & 1.33 & 6.26 & 1.21 & 0.86 & 0.69 & -2.09 & 1.25 & 6.13 \\
\hline
\end{tabular}


577 In order to compare the original SMOS SM with the disaggregated SMOS SM, we filtered the SM

578 products (original and disaggregated SMOS SM) so that only days included in both time-series were

579 included in the evaluation (Figure 10). Disaggregated SMOS SM had a slightly lower correlation than

580 original SMOS SM to in situ SM (Figure 10; $\mathrm{R}^{2}$ in Table 1). However, disaggregated SMOS had a

581 lower bias, a ratio closer to 1.0, a lower RMSE, and it was slightly closer to the one-to-one ratio (slope

5821.21 and 1.26) (Table 1, Figure 10). The largest discrepancy between SMOS SM and the in situ SM

583 was seen for the sites in the southern part of the study area (Belefoungou and Nalohou; Table 1,

584 Figure 10). These are the sites generating the high SMOS SM in the low in situ SM region of Figure

$58510 \mathrm{~g}$. These high SMOS SM values were mainly from the dry season when in situ SM was relatively

586 low (Figure 9b, d).

587 Spatial patterns of disaggregated and original SMOS SM were also evaluated for the entire West

588 Africa (Figure 11). Major river networks (e.g. Niger, Senegal, Hadejia, etc.) are visible in the

589 disaggregated product whereas they are not on the original product (Figure 11b). To assess the

590 potential of the disaggregated SM products for monitoring climate extremes, SM anomalies were

591 estimated for the period July to September (JAS; growing season months in most of West Africa)

5922012 (Figure 11c). Both cases of drought and flooding were observed during that period in West

593 Africa, and negative SM anomalies are seen in most Senegal and Mali, whereas large patterns of

594 positive SM anomalies are observed in Central Mali (Figure 11c). 



Figure 11. SM 2010-2015 average derived from the disaggregated SMOS product over West Africa (a). Main river networks were not visible in the original (non-disaggregated) products (b1), whereas they became apparent after disaggregation (b2). SM extremes (flood and drought) were also captured for the test case of JAS 2012 (c). Filtered and no data are represented in white. The blocky structure observed in the disaggregated products are caused by the original SMOS pixel resolution. 


\section{Discussion}

603

604

605

606

607

608

609

610

611

612

613

614

615

616

617

618

619

620

621

622

623
The use of a higher spatial resolution SM proxy to disaggregate SMOS SM is of high interest as there is a stringent mismatch between the spatial scale at which SM information is provided (e.g. $\sim 40 \mathrm{~km}$ for SMOS) and the scale of the studied process (Collow et al. 2012). Besides the question of the representability of in situ measurements for validating such coarse dataset has often been raised (Dorigo et al. 2015), suggesting that the development of a disaggregated product would grant a more accurate in situ validation (Malbéteau et al. 2016). However, if a systematic bias is present in the original SMOS SM (such as seen for the southern sites (Figure 9), seen in the blocky structure of the final disaggregated product (Figure 5e and Figure 11), and as reported by Collow et al. (2012)), the uncertainty will propagate during the disaggregation process, regardless of the quality of the information used for the disaggregation. One large source of uncertainty for SMOS SM is the presence of forest, being the most likely explanation to the systematic bias in the southern sites (Leroux et al. 2013). The disaggregation of SMOS using TVDI as input data improved the relationship for most sites, suggesting that the TVDI spatial heterogeneity is adequately capturing SM heterogeneity within each SMOS pixel.

One of the major challenges here was to produce a time series of TVDI estimates at sub-continental scale in order to best serve the disaggregation process. Commonly TVDI has been used to evaluate SM or evapotranspiration conditions over regions of limited spatial extent (i.e. hydrological basin, sub-national administrative entities, etc.) (de Tomás et al. 2014; Garcia et al. 2014; Stisen et al. 2008). Here TVDI was estimated using a tile approach of 105 by 105 SEVIRI pixels. By fitting TVDI for such tiles the impact of heterogeneous atmospheric and surface condition were alleviated as much as possible and at the same time made TVDI applicable across the subcontinental study area. 
It is important to note that TVDI values can only be compared within a given tile (Figure 5d). The exact TVDI value estimated for a certain pixel depends on the location of the wet and dry edge and a specific TVDI value will not represent similar local hydrological conditions when fitted over a tile covering humid tropical forest as over a tile covering semi-arid savanna. Besides, TVDI is not only affected by the exact region used for fitting the triangle, but the size of the tile also has a strong influence (Long et al. 2012). With an increase in tile size more humid and dry conditions are included in the triangular space and the wet and dry edge thereby moves up- and down-wards, respectively, with a strong impact on the TVDI estimates (Figure 7) (Long et al. 2012). Additionally, a small tile size causes large uncertainties in the calculation of the wet and dry edges due to the low number of available pixels (Figure 4) (de Tomás et al. 2014), whereas a large tile size induce uncertainty in relation to heterogeneity of surface roughness and atmospheric forcing (Figure 3). As a compromise we used a relatively large tile size as this was deemed necessary to fulfil the requirements of sufficient amount of data-points for TVDI calculations within parts of the study region (Figure 5c).

It is not only challenging to compare TVDI values originating from different tiles but also values derived at the same location but under different meteorological conditions. Indeed, short-term variability in meteorological parameters (e.g. rainfall, temperature, incoming radiation, wind, cloud cover) is likely to impact the temporal variability in TVDI. If we hypothesize that SM temporal variability can be captured by TVDI time series, rainy season TVDI should be substantially lower than dry season TVDI. As this pattern is not observed (Figure 6), it leads to the questioning of the applicability of TVDI as proxy for monitoring the SM temporal variability. This finding however do not disqualify TVDI as proxy for assessing the spatial variability of SM within a given tile. Here the tile size was set so that a SMOS pixel is never overlapping two different tiles; and each pixel only uses the TVDI heterogeneity within a tile and at a certain point in time for disaggregation of SMOS SM. Future research related to the improvement of the temporal patterns of TVDI could possibly 
focus on the use of the newly launched geostationary satellite GOES-R with 1-km spatial resolution which will improve the ability to acquire pure pixels for a comparable smaller area or by using data from constellations of polar orbiting sensors (e.g. MODIS, VIIRS and Sentinel-3) ensuring higher spatial resolution in combination with an adequate temporal resolution.

The TVDI retrievals were found to be very sensitive to errors in the input parameters at the upper range of FVC, challenging the applicability of the TVDI approach for the high FVC regions needed to shape the triangular space. Indeed, it has previously been shown that DisPATCH in the form that it was implemented in this study performs better over semi-arid areas than over temperate zones (Malbéteau et al. 2016). It has also been found that the triangular method underestimates evapotranspiration because the surface temperature of empirically retrieved dry and wet edges are usually under- and overestimated, respectively (Tang and Li 2015). In reality, the evapotranspiration and SM should reach a minimum and maximum level at surface temperatures higher than and lower than what the actual observations show (Tang and Li 2015). This is specifically the case for the upper part of the FVC range (Tang et al. 2010). Incorporating a theoretical dry and wet edge higher and lower than the actual measured level would decrease the sensitivity of the disaggregated product to the input parameters, given that the wet and dry edge would be displaced from the observed values. Tang and Li (2017) developed a physically based model for estimates of endmembers of a trapezoid for evapotranspiration estimates based on both data from earth observation and in situ measurements (meteorology, incoming short and longwave radiation, and vegetation height). It is possible that this approach could be adjusted and applied to earth observation and gridded meteorological and vegetation data for estimating endmembers giving such theoretical dry and wet edges. Possibly, this would also result in larger temporal (seasonal) dynamics in TVDI since high FVC observations (i.e. growing season conditions) would be more influenced than low FVC observations (dry season conditions). 
672 Despite these inherent limitations of the TVDI approach, TVDI is found to be a valuable approach 673 for the purpose of disaggregating SM of a SMOS pixel as implemented here. The accuracy of the 674 disaggregated products (RMSE 3.4-10.6\%Vol) were at a similar level as previously published 675 disaggregated SMOS SM products (RMSE varying between 3-11\%Vol) for a range of vegetation 676 types covered here (semi-arid woody savannah, cultivated semi-arid regions, humid woody savannah 677 and tropical forest) (Djamai et al. 2015; Malbéteau et al. 2016; Merlin et al. 2013; Peng et al. 2017; 678 Piles et al. 2016; Piles et al. 2014). Increased details related to major river networks confirms that the 679 disaggregation method driven by the TVDI spatial heterogeneity was successful in improving the 680 spatial representation of the hydrological landscape over West Africa (Figure 11). SM extremes were

681

682

683

684

685

686

687

688

689

690

691

692

693

694

695 depicted adequately for the test case of JAS 2012 that coincided with a complex food security crisis in the Sahel. During that year, late, erratic rainfall, together with high food prices and chronic poverty pushed more than 19 million people into food insecurity in the Sahel (de Robert 2012). In August countries already affected by the drought were then hit by heavy rainfall (e.g. in Central Mali, and in several regions in Niger and Nigeria) causing flooding, destroyed infrastructure and damaged crop fields (FEWSNET 2012a, b). Despite the relatively short length of available time series (max. 5 years), seasonal anomalies derived from the disaggregated SM product proved to be an adequate tool to identify both areas affected by extreme high and low SM content. Further investigations should focus on the evaluation of potential monitoring and early warning products at monthly or lower time scale derived from the disaggregated product.

Overall it can be concluded that the disaggregation methodology successfully increased the spatial resolution of SMOS SM and that the disaggregated products can potentially be applied to local SM monitoring for drought/flood risks which is of significant importance for the livelihood of the population in West Africa. Initiatives such as the one set by the European Space Agency (ESA) Data User Element (DUE) GlobTemperature Project that aims at producing and distributing high quality, 
consistent LST dataset are of high value for climate and hydrological studies, especially in remote areas with low density in situ SM networks. Further research effort should therefore continue the development and distribution of very high temporal time series of LST that are essential for specific activities related to the better understanding of the hydrological cycle, the monitoring, forecasting and early warning of extreme events.

\section{Acknowledgements}

We would like to thank the anonymous reviewers for detailed and constructive comments. FVC were provided by the EUMETSAT Satellite Application Facility on Land Surface Analysis (LSA SAF, http://landsaf.ipma.pt). The authors would like to thank Radoslav Guzinski for providing the code for the TVDI computation. This study was funded by the European Space Agency (ESA) Data User Element (DUE) GlobTemperature Project. Torbern Tagesson was additionally funded by the Swedish national Space board (SNSB Dnr 95/16). Stephanie Horion was additionally funded by the Belgian Science Policy office in the frame of the STEREO III U-TURN project.Torbern Tagesson, Stephanie Horion and Rasmus Fensholt were also funded by Danish Council for Independent Research (DFF) Greening of drylands (DFF-6111-00258): Towards understanding ecosystem functioning changes, drivers and impacts on livelihoods..

\section{References}

Alcaraz-Segura, D., Liras, E., Tabik, S., Paruelo, J., \& Cabello, J., 2010. Evaluating the Consistency of the 1982-1999 NDVI Trends in the Iberian Peninsula across Four Time-series Derived from the AVHRR Sensor: LTDR, GIMMS, FASIR, and PAL-II. Sensors 10, 1291-1314

Anderson, M.C., Norman, J.M., Mecikalski, J.R., Otkin, J.A., \& Kustas, W.P., 2007. A climatological study of evapotranspiration and moisture stress across the continental United States based on thermal remote sensing: 2. Surface moisture climatology. J. Geophys. Res. -Atmos. 112, $\mathrm{n} / \mathrm{a}-\mathrm{n} / \mathrm{a}$ 
732

733

734

735

736

737

738

739

740

Bach, H., \& Mauser, W., 1994. Modelling and model verification of the spectral reflectance of soils under varying moisture conditions, Proceedings of IGARSS '94 - 1994 IEEE International Geoscience and Remote Sensing Symposium, Pasadena, CA, USA

Bonan, G., 2008. Ecological Climatology: Concepts and Applications. Cambridge University Press, New York

Carlson, T.N., Gillies, R.R., \& Schmugge, T.J., 1995. An Interpretation of Methodologies for Indirect Measurement of Soil-Water Content. Agric. For. Meteorol. 77, 191-205

Carlson, T.N., Perry, E.M., \& Schmugge, T.J., 1990. Remote Estimation of Soil-Moisture Availability and Fractional Vegetation Cover for Agricultural Fields. Agric. For. Meteorol. 52, 4569

Collow, T.W., Robock, A., Basara, J.B., \& Illston, B.G., 2012. Evaluation of SMOS retrievals of soil moisture over the central United States with currently available in situ observations. $J$. Geophys. Res.-Atmos. 117

Crago, R., \& Brutsaert, W., 1996. Daytime evaporation and the self-preservation of the evaporative fraction and the Bowen ratio. J. Hydrol. 178, 241-255

de Beurs, K.M., \& Henebry, G.M., 2005. A statistical framework for the analysis of long image time series. Int. J. Remote Sens. 26, 1551-1573

de Robert, G., 2012. Sahel Food Crisis 2012 - A Cyclical or Exceptional Crisis?, Rome, FAO report, pp. 6

de Tomás, A., Nieto, H., Guzinski, R., Salas, J., Sandholt, I., \& Berliner, P., 2014. Validation and scale dependencies of the triangle method for the evaporative fraction estimation over heterogeneous areas. Remote Sens. Environ. 152, 493-511

Djamai, N., Magagi, R., Goita, K., Merlin, O., Kerr, Y., \& Walker, A., 2015. Disaggregation of SMOS soil moisture over the Canadian Prairies. Remote Sens. Environ. 170, 255-268

Dorigo, W.A., Gruber, A., De Jeu, R.A.M., Wagner, W., Stacke, T., Loew, A., Albergel, C., Brocca, L., Chung, D., Parinussa, R.M., \& Kidd, R., 2015. Evaluation of the ESA CCI soil moisture product using ground-based observations. Remote Sens. Environ. 162, 380-395

Eastman, R., Sangermano, F., Ghimire, B., Zhu, H., Chen, H., Neeti, N., Cai, Y., Machado, E.A., \& Crema, S.C., 2009. Seasonal trend analysis of image time series. Int. J. Remote Sens. 30, 2721-2726 
790

791

792

793

794

795

796

797

798

799

800

801

ECMWF, 2017. ERA5.

https://software.ecmwf.int/wiki/display/CKB/How+to+download+ERA5+data+via+the+ECMWF+

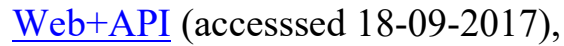

FEWSNET, 2012a. Mali Food Security Outlook update. www.fews.net/mali (accesssed 03-052017),

FEWSNET, 2012b. West Africa Food Security Outlook Update. http://www.fews.net/westafrica/food-security-outlook-update/september-2012 (accesssed 03-05-2017),

García-Haro, F.J., Sommer, S., \& Kemper, T., 2005. A new tool for variable multiple endmember spectral mixture analysis (VMESMA). Int. J. Remote Sens. 26, 2135-2162

Garcia, M., Fernández, N., Villagarcía, L., Domingo, F., Puigdefábregas, J., \& Sandholt, I., 2014. Accuracy of the Temperature-Vegetation Dryness Index using MODIS under water-limited vs. energy-limited evapotranspiration conditions. Remote Sens. Environ. 149, 100-117

Gillies, R.R., \& Carlson, T.N., 1995. Thermal Remote-Sensing of Surface Soil-Water Content with Partial Vegetation Cover for Incorporation into Climate-Models. J. Appl. Meteorol. 34, 745-756

GLOBTEMP, 2014. GLOBTEMPERATURE- an ESA DUE initiative. http://globtemperature.info/ (accesssed 2017-10-16),

Han, Y., Wang, Y.Q., \& Zhao, Y.S., 2010. Estimating Soil Moisture Conditions of the Greater Changbai Mountains by Land Surface Temperature and NDVI. IEEE T. Geosci. Remote Sens. 48, 2509-2515

Hassan, Q.K., Bourque, C.P.A., Meng, F.R., \& Cox, R.M., 2007. A wetness index using terraincorrected surface temperature and normalized difference vegetation index derived from standard MODIS products: An evaluation of its use in a humid forest-dominated region of eastern Canada. Sensors 7, 2028-2048

Hirsch, R.M., \& Slack, J.R., 1984. A Nonparametric Trend Test for Seasonal Data with Serial Dependence. Water Resour. Res. 20, 727-732

ISMN, 2016. The International Soil Moisture Network. https://ismn.geo.tuwien.ac.at/ (accesssed 14-02-2016), 
Jiang, Z.Y., Huete, A.R., Didan, K., \& Miura, T., 2008. Development of a two-band enhanced vegetation index without a blue band. Remote Sens. Environ. 112, 3833-3845

Jimenez-Munoz, J.C., \& Sobrino, J.A., 2008. Split-Window Coefficients for Land Surface Temperature Retrieval From Low-Resolution Thermal Infrared Sensors. IEEE Geosci. Remote Sens. Lett. 5, 806-809

Kerr, Y.H., 2007. Soil moisture from space: Where are we? Hydrogeol. J. 15, 117-120

Kerr, Y.H., Font, J., Martin-Neira, M., \& Mecklenburg, S., 2012. Introduction to the Special Issue on the ESA's Soil Moisture and Ocean Salinity Mission (SMOS)-Instrument Performance and First Results. IEEE T. Geosci. Remote Sens. 50, 1351-1353

Kustas, W.P., \& Norman, J.M., 1999. Evaluation of soil and vegetation heat flux predictions using a simple two-source model with radiometric temperatures for partial canopy cover. Agric. For.

Meteorol. 94, 13-29

Leroux, D.J., Kerr, Y.H., Richaume, P., \& Fieuzal, R., 2013. Spatial distribution and possible sources of SMOS errors at the global scale. Remote Sens. Environ. 133, 240-250

Li, H.J., Li, C.Q., Lin, Y., \& Lei, Y.P., 2010. Surface temperature correction in TVDI to evaluate soil moisture over a large area. J. Food Agric. Environ. 8, 1141-1145

Li, Z.G., Wang, Y.L., Zhou, Q.B., Wu, J.S., Peng, J., \& Chang, H.F., 2008. Spatiotemporal variability of land surface moisture based on vegetation and temperature characteristics in Northern Shaanxi Loess Plateau, China. J. Arid Environ. 72, 974-985

Long, D., Singh, V.P., \& Scanlon, B.R., 2012. Deriving theoretical boundaries to address scale dependencies of triangle models for evapotranspiration estimation. J. Geophys. Res. -Atmos. 117, D05113

Louvet, S., Pellarin, T., al Bitar, A., Cappelaere, B., Galle, S., Grippa, M., Gruhier, C., Kerr, Y., Lebel, T., Mialon, A., Mougin, E., Quantin, G., Richaume, P., \& de Rosnay, P., 2015. SMOS soil moisture product evaluation over West-Africa from local to regional scale. Remote Sens. Environ. $156,383-394$

Malbéteau, Y., Merlin, O., Molero, B., Rüdiger, C., \& Bacon, S., 2016. DisPATCh as a tool to evaluate coarse-scale remotely sensed soil moisture using localized in situ measurements: Application to SMOS and AMSR-E data in Southeastern Australia. Int. J. Appl. Earth Obs. Geoinf. $45,221-234$ 
Mallick, K., Bhattacharya, B.K., \& Patel, N.K., 2009. Estimating volumetric surface moisture content for cropped soils using a soil wetness index based on surface temperature and NDVI. Agric. For. Meteorol. 149, 1327-1342

Merlin, O., Al Bitar, A., Walker, J.P., \& Kerr, Y., 2010. An improved algorithm for disaggregating microwave-derived soil moisture based on red, near-infrared and thermal-infrared data. Remote Sens. Environ. 114, 2305-2316

Merlin, O., Escorihuela, M.J., Mayoral, M.A., Hagolle, O., Al Bitar, A., \& Kerr, Y., 2013. Selfcalibrated evaporation-based disaggregation of SMOS soil moisture: An evaluation study at $3 \mathrm{~km}$ and $100 \mathrm{~m}$ resolution in Catalunya, Spain. Remote Sens. Environ. 130, 25-38

Merlin, O., Rudiger, C., Al Bitar, A., Richaume, P., Walker, J.P., \& Kerr, Y.H., 2012.

Disaggregation of SMOS Soil Moisture in Southeastern Australia. IEEE T. Geosci. Remote Sens. $50,1556-1571$

Minacapilli, M., Iovino, M., \& Blanda, F., 2009. High resolution remote estimation of soil surface water content by a thermal inertia approach. J. Hydrol. 379, 229-238

Moran, M.S., Clarke, T.R., Inoue, Y., \& Vidal, A., 1994. Estimating Crop Water-Deficit Using the Relation between Surface-Air Temperature and Spectral Vegetation Index. Remote Sens. Environ. 49, 246-263

Moran, M.S., Peters-Lidard, C.D., Watts, J.M., \& McElroy, S., 2004. Estimating soil moisture at the watershed scale with satellite-based radar and land surface models. Can. J. Remote Sens. 30, 805-826

Nieto, H., Sandholt, I., Aguado, I., Chuvieco, E., \& Stisen, S., 2011. Air temperature estimation with MSG-SEVIRI data: Calibration and validation of the TVX algorithm for the Iberian Peninsula. Remote Sens. Environ. 115, 107-116

Noilhan, J., \& Planton, S., 1989. A Simple Parameterization of Land Surface Processes for Meteorological Models. Monthly Weather Review 117, 536-549

Panciera, R., Walker, J.P., Jackson, T.J., Gray, D.A., Tanase, M.A., Ryu, D., Monerris, A., Yardley, H., Rudiger, C., Wu, X.L., Gao, Y., \& Hacker, J.M., 2014. The Soil Moisture Active Passive Experiments (SMAPEx): Toward Soil Moisture Retrieval From the SMAP Mission. IEEE T. Geosci. Remote Sens. 52, 490-507 
892

893

894

895

896

897

898

899

900

901

902

903

904

905

906

907

908

909

910

911

912

913

914

915

916

917

918

919

920

921
Patel, N.R., Anapashsha, R., Kumar, S., Saha, S.K., \& Dadhwal, V.K., 2009. Assessing potential of MODIS derived temperature/vegetation condition index (TVDI) to infer soil moisture status. Int. J. Remote Sens. 30, 23-39

Peng, J., Loew, A., Merlin, O., \& Verhoest, N.E.C., 2017. A review of spatial downscaling of satellite remotely sensed soil moisture. Reviews of Geophysics 55, 341-366

Piles, M., Petropoulos, G.P., Sánchez, N., González-Zamora, Á., \& Ireland, G., 2016. Towards improved spatio-temporal resolution soil moisture retrievals from the synergy of SMOS and MSG SEVIRI spaceborne observations. Remote Sens. Environ. 180, 403-417

Piles, M., Sánchez, N., Vall-1lossera, M., Camps, A., Martínez-Fernández, J., Martínez, J., \& González-Gambau, V., 2014. A Downscaling Approach for SMOS Land Observations: Evaluation of High-Resolution Soil Moisture Maps Over the Iberian Peninsula. IEEE J. Sel. Top. Appl. 7, 3845-3857

Price, J.C., 1990. Using Spatial Context in Satellite Data to Infer Regional Scale Evapotranspiration. IEEE T. Geosci. Remote Sens. 28, 940-948

Proud, S.R., Rasmussen, M.O., Fensholt, R., Sandholt, I., Shisanya, C., Mutero, W., Mbow, C., \& Anyamba, A., 2010. Improving the SMAC atmospheric correction code by analysis of Meteosat Second Generation NDVI and surface reflectance data. Remote Sens. Environ. 114, 1687-1698

Proud, S.R., Zhang, Q., Schaaf, C., Fensholt, R., Rasmussen, M.O., Shisanya, C., Mutero, W., Mbow, C., Anyamba, A., Pak, E., \& Sandholt, I., 2014. The Normalization of Surface Anisotropy Effects Present in SEVIRI Reflectances by Using the MODIS BRDF Method. IEEE T. Geosci. Remote Sens. 52, 6026-6039

Rasmussen, M.O., Gottsche, F.M., Olesen, F.S., \& Sandholt, I., 2011. Directional Effects on Land Surface Temperature Estimation From Meteosat Second Generation for Savanna Landscapes. IEEE T. Geosci. Remote Sens. 49, 4458-4468

Sadeghi, M., Jones, S.B., \& Philpot, W.D., 2015. A linear physically-based model for remote sensing of soil moisture using short wave infrared bands. Remote Sens. Environ. 164, 66-76

Sandholt, I., Rasmussen, K., \& Andersen, J., 2002. A simple interpretation of the surface temperature/vegetation index space for assessment of surface moisture status. Remote Sens. Environ. 79, 213-224

Schmugge, T., 1978. Remote-Sensing of Surface Soil-Moisture. J. Appl. Meteorol. 17, 1549-1557 
Sobrino, J.A., \& Romaguera, M., 2004. Land surface temperature retrieval from MSG1-SEVIRI data. Remote Sens. Environ. 92, 247-254

Stisen, S., Sandholt, I., Norgaard, A., Fensholt, R., \& Jensen, K.H., 2008. Combining the triangle method with thermal inertia to estimate regional evapotranspiration - Applied to MSG-SEVIRI data in the Senegal River basin. Remote Sens. Environ. 112, 1242-1255

Stisen, S., Sandholt, I., Nørgaard, A., Fensholt, R., \& Eklundh, L., 2007. Estimation of diurnal air temperature using MSG SEVIRI data in West Africa. Remote Sens. Environ. 110, 262-274

Sun, L., Sun, R., Li, X.W., Liang, S.L., \& Zhang, R.H., 2012. Monitoring surface soil moisture status based on remotely sensed surface temperature and vegetation index information. Agric. For. Meteorol. 166, 175-187

Tagesson, T., Fensholt, R., Cappelaere, B., Mougin, E., Horion, S., Kergoat, L., Nieto, H., Ehammer, A., Demarty, J., \& Ardö, J., 2016. Spatiotemporal variability in carbon exchange fluxes across the Sahel Agric. For. Meteorol. 226-227, 108-118

Tagesson, T., Fensholt, R., Guiro, I., Rasmussen, M.O., Huber, S., Mbow, C., Garcia, M., Horion, S., Sandholt, I., Rasmussen, B.H., Göttsche, F.M., Ridler, M.-E., Olén, N., Olsen, J.L., Ehammer, A., Madsen, M., Olesen, F.S., \& Ardö, J., 2015. Ecosystem properties of semi-arid savanna grassland in West Africa and its relationship to environmental variability. Global Change Biol. 21, 250-264

Tang, R., \& Li, Z.-L., 2015. Evaluation of two end-member-based models for regional land surface evapotranspiration estimation from MODIS data. Agric. For. Meteorol. 202, 69-82

Tang, R., \& Li, Z.L., 2017. An End-Member-Based Two-Source Approach for Estimating Land Surface Evapotranspiration From Remote Sensing Data. IEEE T. Geosci. Remote Sens. PP, 1-15

Tang, R.L., Li, Z.L., \& Tang, B.H., 2010. An application of the T-s-VI triangle method with enhanced edges determination for evapotranspiration estimation from MODIS data in and and semiarid regions: Implementation and validation. Remote Sens. Environ. 114, 540-551

Trigo, I.F., Dacamara, C.C., Viterbo, P., Roujean, J.-L., Olesen, F., Barroso, C., Camacho-de-Coca, F., Carrer, D., Freitas, S.C., García-Haro, J., Geiger, B., Gellens-Meulenberghs, F., Ghilain, N., Meliá, J., Pessanha, L., Siljamo, N., \& Arboleda, A., 2011. The Satellite Application Facility for Land Surface Analysis. Int. J. Remote Sens. 32, 2725-2744 
971

972

973

974

975

976

977

978

979

980

981

982

983

984

985

986

987

988

989

990

991

992

993

994

995

Trigo, I.F., Peres, L.F., DaCamara, C.C., \& Freitas, S.C., 2008. Thermal Land Surface Emissivity Retrieved From SEVIRI/Meteosat. IEEE T. Geosci. Remote Sens. 46, 307-315

Vanbelle, G., \& Hughes, J.P., 1984. Nonparametric-Tests for Trend in Water-Quality. Water Resour. Res. 20, 127-136

Vinukollu, R.K., Wood, E.F., Ferguson, C.R., \& Fisher, J.B., 2011. Global estimates of evapotranspiration for climate studies using multi-sensor remote sensing data: Evaluation of three process-based approaches. Remote Sens. Environ. 115, 801-823

Wan, Z.M., \& Dozier, J., 1996. A generalized split-window algorithm for retrieving land-surface temperature from space. IEEE T. Geosci. Remote Sens. 34, 892-905

Wang, C.Y., Qi, S.H., Niu, Z., \& Wang, J.B., 2004. Evaluating soil moisture status in China using the temperature-vegetation dryness index (TVDI). Can. J. Remote Sens. 30, 671-679

Wang, J., Ling, Z., Wang, Y., \& Zeng, H., 2016. Improving spatial representation of soil moisture by integration of microwave observations and the temperature-vegetation-drought index derived from MODIS products. ISPRS Journal of Photogrammetry and Remote Sensing 113, 144-154

Wang, K.C., Li, Z.Q., \& Cribb, M., 2006. Estimation of evaporative fraction from a combination of day and night land surface temperatures and NDVI: A new method to determine the PriestleyTaylor parameter. Remote Sens. Environ. 102, 293-305

Wigneron, J.P., Kerr, Y., Waldteufel, P., Saleh, K., Escorihuela, M.J., Richaume, P., Ferrazzoli, P., de Rosnay, P., Gurney, R., Calvet, J.C., Grant, J.P., Guglielmetti, M., Hornbuckle, B., Mätzler, C., Pellarin, T., \& Schwank, M., 2007. L-band Microwave Emission of the Biosphere (L-MEB) Model: Description and calibration against experimental data sets over crop fields. Remote Sens. Environ. 107, 639-655

\section{Appendix A. Mathematical derivations of Equation 5 and 7}

\section{Equation 5 was derived from equation 4:}

$$
\mathrm{SEE}_{\text {model }}=\frac{1}{2}-\frac{1}{2} \cos \left(\pi \times \frac{\mathrm{SM}}{\mathrm{SM}_{\mathrm{p}}}\right)
$$

\footnotetext{
Multiply both sides with -2 :
} 
$996-2 \mathrm{SEE}_{\text {model }}=-1+\cos \left(\pi \times \frac{\mathrm{SM}}{\mathrm{SM}_{\mathrm{p}}}\right)$

997 Add 1 to both sides:

$998 \quad 1-2 \mathrm{SEE}_{\text {model }}=\cos \left(\pi \times \frac{\mathrm{SM}}{\mathrm{SM}_{\mathrm{p}}}\right)$

999 Multiply both sides with arccos:

$1000 \arccos \left(1-2 \mathrm{SEE}_{\text {model }}\right)=\pi \times \frac{\mathrm{SM}}{\mathrm{SM}_{\mathrm{p}}}$

1001 Put $\mathrm{SM}_{\mathrm{p}}$ on the left side and put $\arccos \left(1-2 \mathrm{SEE}_{\text {model }}\right)$ in the denominator on the right side and 1002 equation 5 is derived:

$1003 \quad \mathrm{SM}_{\mathrm{p}}=\frac{\pi \times \mathrm{SM}_{\mathrm{SMOS}}}{\arccos \left(1-2\left\langle\mathrm{SEE}_{\mathrm{SEVIRI}}\right\rangle_{\mathrm{SMOS}}\right)}$

\section{Equation 7 was derived by taking the derivative of equation 6:}

1005

$1006 \quad \mathrm{SM}_{\text {model }}=\frac{\mathrm{SM}_{\mathrm{p}}}{\pi} \arccos (1-2 \mathrm{SEE})$

1007 The derivative of $\arccos (\mathrm{x})$ is:

$1008 \frac{\partial \operatorname{arcc}(x)}{\partial \mathrm{x}}=-\frac{1}{\sqrt{1-\mathrm{x}^{2}}}$

1009 Then, by setting $\mathrm{x}=(1-2 \mathrm{SEE})$ and taking the derivative of $\mathrm{x}$ we get:

$1010 \quad \frac{\partial \mathrm{S} \text { model }}{\partial \mathrm{x}}=-\frac{\frac{\mathrm{SM}_{\mathrm{p}}}{\pi}}{\sqrt{1-\mathrm{x}^{2}}}$

1011 Then by taking the derivative of SEE on $\mathrm{x}$ we get: 
$1012 \frac{\partial x}{\partial \mathrm{SEE}}=-2$

1013 Then by multiplying both sides with the derivative of SEE on $\mathrm{x}$ we get:

$1014 \frac{\partial \mathrm{SM}_{\text {model }}}{\partial \mathrm{x}} \times \frac{\partial x}{\partial \mathrm{SEE}}=-\frac{\frac{\mathrm{SM}_{\mathrm{p}}}{\pi}}{\sqrt{1-\mathrm{x}^{2}}} \times-2 \Rightarrow \frac{\partial \mathrm{SM}_{\text {model }}}{\partial \mathrm{SEE}}=\frac{2\left(\frac{\mathrm{SM}_{\mathrm{p}}}{\pi}\right)}{\sqrt{1-\mathrm{x}^{2}}}$

1015 Finally, by setting $\mathrm{x}=(1-2 \mathrm{SEE})$ equation 7 is derived:

$1016 \frac{\partial \mathrm{SM}_{\text {model }}}{\partial \mathrm{SEE}}=\frac{2\left(\frac{\mathrm{SM}_{\mathrm{p}}}{\pi}\right)}{\sqrt{1-(1-2 \mathrm{SE})^{2}}}$

1017

1018

\section{Appendix B. Mathematical derivations indicating that TVDI is a proxy of SEE}

1019

1020

According Merlin et al. (2012) SEE can be calculated as:

$\mathrm{SEE}=\frac{\mathrm{T}_{\text {soil_max }}-\mathrm{T}_{\text {soil }}}{\mathrm{T}_{\text {soil_max }}-\mathrm{T}_{\text {soil_min }}}$

1021 where $\mathrm{T}_{\text {soil }}$ is the soil temperature; $\mathrm{T}_{\text {soil_min }}$ is minimum $\mathrm{T}_{\text {soil }}$; and $\mathrm{T}_{\text {soil_max }}$ is maximum $\mathrm{T}_{\text {soil. }}$.

1022 Soil temperature and $T_{\text {soil_max }}$ can be calculated as (Merlin et al. 2010; Merlin et al. 2012):

$1023 \quad \mathrm{~T}_{\text {soil }}=\frac{\text { LST }-\left(\mathrm{FVC} \times \mathrm{T}_{\text {vegetation }}\right)}{1-\left(\mathrm{FVC} \times \mathrm{T}_{\text {vegetation }}\right)}$

$1024 \mathrm{~T}_{\text {soil_max }}=\frac{\mathrm{LST}_{\max }-\left(\mathrm{FVC} \times \mathrm{T}_{\text {vegetation }}\right)}{1-\left(\mathrm{FVC} \times \mathrm{T}_{\text {vegetation }}\right)}$

1025 If we put these two into equation B1; we get:

1026

$\mathrm{SEE}=\frac{\frac{\mathrm{LST}_{\max }-\left(\mathrm{FVC} \times \mathrm{T}_{\text {vegetation }}\right)}{(1-\mathrm{FVC})}-\frac{\mathrm{LST}-\left(\mathrm{FVC} \times \mathrm{T}_{\text {vegetation }}\right)}{(1-\mathrm{FVC})}}{\frac{\mathrm{LST}_{\max }-\left(\mathrm{FVC} \times \mathrm{T}_{\text {vegetation }}\right)}{(1-\mathrm{FVC})}-\mathrm{T}_{\text {soil_min }}}$

$=>$

$\mathrm{SEE}=\frac{\frac{\mathrm{LST}_{\max }-\left(\mathrm{FVC} \times \mathrm{T}_{\text {vegetation }}\right)}{(1-\mathrm{FVC})}-\frac{\mathrm{LST}-\left(\mathrm{FVC} \times \mathrm{T}_{\text {vegetation }}\right)}{(1-\mathrm{FVC})}}{\frac{\mathrm{LST}_{\max }-\left(\mathrm{FVC} \times \mathrm{T}_{\text {vegetation }}\right)}{(1-\mathrm{FVC})}-\frac{\mathrm{T}_{\text {soil_min }}(1-\mathrm{FVC})}{(1-\mathrm{FVC})}}$

1028

$\mathrm{SEE}=\frac{\mathrm{LST}_{\max }-\left(\mathrm{FVC} \times \mathrm{T}_{\text {vegetation }}\right)-\mathrm{LST}+\left(\mathrm{FVC} \times \mathrm{T}_{\text {vegetation }}\right)}{\mathrm{LST}_{\max }-\left(\mathrm{FVC} \times \mathrm{T}_{\text {vegetation }}\right)-\mathrm{T}_{\text {soil_min }}(1-\mathrm{FVC})} \quad \Rightarrow$ 
$1035 \mathrm{SEE} \approx \frac{\mathrm{LST}_{\max }-\mathrm{LST}}{\mathrm{LST}_{\max }-\mathrm{T}_{\text {soil }_{\min }}} \approx \frac{\mathrm{LST}_{\max }-\mathrm{LST}}{\mathrm{LST}_{\max }-\mathrm{LST}_{\min }}=(1-\mathrm{TVDI})$ 
1037

1038

1039

1040

1041

1042

1043

1044

1045

1046

1047

1048

1049

1050

1051

1052

1053

1054

1055

1056

1057

1058

1059

1060

1061

1062

1063

1064

1065

1066

1067

1068

1069

1070

1071

1072

1073

1074

1075

\section{Figure Captions}

Figure 1. Conceptual triangle space with the land surface temperature (LST) or morning rise temperature (dTS) on the y-axis and Fraction of Vegetation Cover (FVC) on the x-axis. The blue line is the wet edge (TVDI $=0.00$ ) and the red line is the dry edge (TVDI=1.00). The grey dotted lines are TVDI examples of $0.25,0.50$, and 0.75 . The figure is adapted from Peng et al. (2017).

Figure 2. Study area with the location of the in situ validation sites. The averaged fraction of vegetation cover (FVC) for year 2011 is used as background to illustrate the important north-south gradient in vegetation cover.

Figure 3. Dynamic range in surface properties and atmospheric forcing influencing the homogeneity of available energy within the triangular space. Influence of tile size (y-axis) on the percentiles of the time series (x-axis) of the dynamic range in daily averaged a) forecast surface roughness (FSR) (m); b), surface solar radiation downwards (SSRD) $\left(\mathrm{W} \mathrm{m}^{-2}\right)$; c) total column water vapour (TCWV) $(\mathrm{kg}$ $\left.\mathrm{m}^{-2}\right)$; d) wind speed at $100 \mathrm{~m}$ height (WS) $\left(\mathrm{m} \mathrm{s}^{-1}\right)$; and e) air temperature at the $975 \mathrm{hPa}$ level ( $\left.\mathrm{T}_{\text {air }}\right)$ (K) for 1) the Dahra and 2) the Nalohou field sites. The percentiles on the $\mathrm{x}$-axis gives an indication of the fraction of the time series for a given tile size having a dynamic range smaller than the value shown by the colour. For the z-axis, dark blue indicates high homogeneity (i.e. small dynamic range) in surface properties or atmospheric forcing, whereas yellow indicates low homogeneity.

Figure 4. Influence of tile size (y-axis) on the percentiles of the time series (x-axis) of the parameters influencing the triangular shape. a) Number of points including in the triangle $(\mathrm{N})$; b) range in fraction of vegetation cover (FVC); and c) correlation coefficient of the dry edge slope (r) for 1) the Dahra and, 2) the Nalohou field sites. The percentiles on the x-axis gives an indication of the fraction of the time-series for a given tile size having a range smaller than the value shown by the colour.

Figure 5. (a) Fraction of data coverage for the input data (dTS and FVC) used in the TVDI calculations; (b) fraction of data coverage for the TVDI calculations when TVDI was filtered based on both TVDI tile statistics and quality flags in input data. (c) Average data exclusion fraction depending on latitude; blue is the fraction of rejected input data, red is the fraction rejected in relation to the TVDI calculation, and black is the total rejected fraction. Included are also: (d) average TVDI for the entire study period; and (e) disaggregated SMOS SM averaged for the entire study period.

Figure 6. Time series of the input parameters, extracts from the TVDI calculation tiles, and final TVDI estimates for (1) Dahra and (2) Nalohou: (a,) fraction of vegetation cover (FVC); (b) unfiltered (red) and filtered (black) morning rise temperature (dTS); (c) range of FVC in the TVDI tiles; (d) 
total number of points included in the triangle $(\mathrm{N})$; (e) coefficient of determination $\left(\mathrm{R}^{2}\right)$ for the dry edge fit; (f) wet edge; and (g) dry edge slope. Included are also (h) filtered (black) and gap-filled (red) TVDI estimates (black).

Figure 7. Sensitivity of TVDI to input data and equation parameters: a) morning rise temperature $\left(\mathrm{dTS} ;{ }^{\circ} \mathrm{C}\right)$; b) fraction of vegetation cover (FVC); c) dry edge intercept (DI); d) dry edge slope (DS); and e) wet edge (W). The \% for the temperatures (dTS, DI, and W) and the FVC is a \% change in relation to the range of the triangle. During the analysis we changed one parameter at the time and the rest remained stable.

Figure 8. Sensitivity of disaggregated SMOS soil moisture (SM; \%Vol) to changes in TVDI. Average TVDI in equation 8 was set to a) 0.25 , b) 0.50 and c) 0.75 . First row (1) shows the actual disaggregated SM for each original SMOS SM -TVDI case and second row (2) shows the changes in disaggregated SM for each 0.01 error in TVDI for each SM -TVDI case.

Figure 9. Time series of in situ measured soil moisture (SM (\%Vol)) (thin black line) and Soil moisture and Ocean Salinity (SMOS) SM (grey dots) for: a) Banizoumbou; b) Belefoungou; c) Dahra; d) Nalohou e) Tondikiboro; and f) Wankama. The location of the different sites is shown in Figure 2.

Figure 10. Relationship between in situ and both original (1) and disaggregated (2) Soil Moisture and Ocean Salinity (SMOS) soil moisture (SM; \% Vol) for the pixels used in the evaluation of the disaggregation methodology. The subplots are: a) Banizoumbou; b) Belefoungou; c) Dahra; d) Nalohou; e) Tondikiboro; f) Wankama; and g) all sites combined. The grey line is the ordinary least square linear regression and the black line is the one-to-one ratio. Statistics of the slopes are given in Table 1 . The location of the sites can be seen in figure 2 .

Figure 11. SM 2010-2015 average derived from the disaggregated SMOS product over West Africa (a). Main river networks were not visible in the original (non-disaggregated) products (b1), whereas they became apparent after disaggregation (b2). SM extremes (flood and drought) were also captured for the test case of JAS 2012 (c). Filtered and no data are represented in white. The blocky structure observed in the disaggregated products are caused by the original SMOS pixel resolution. 